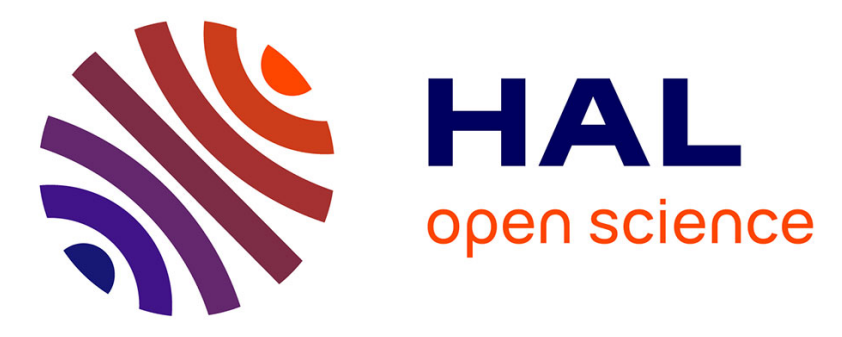

\title{
Biophysical forces rewire cell metabolism to guide microtubule-dependent cell mechanics
}

Stephanie Torrino, Stéphane Audebert, Ilyes Belhadj, Caroline Lacoux, Sabrina Pisano, Sophie Abélanet, Frederic Brau, Stephen y Chan, Bernard Mari, William M Oldham, et al.

\section{To cite this version:}

Stephanie Torrino, Stéphane Audebert, Ilyes Belhadj, Caroline Lacoux, Sabrina Pisano, et al.. Biophysical forces rewire cell metabolism to guide microtubule-dependent cell mechanics. 2020. hal03045825

\section{HAL Id: hal-03045825 \\ https://hal.science/hal-03045825}

Preprint submitted on 8 Dec 2020

HAL is a multi-disciplinary open access archive for the deposit and dissemination of scientific research documents, whether they are published or not. The documents may come from teaching and research institutions in France or abroad, or from public or private research centers.
L'archive ouverte pluridisciplinaire HAL, est destinée au dépôt et à la diffusion de documents scientifiques de niveau recherche, publiés ou non, émanant des établissements d'enseignement et de recherche français ou étrangers, des laboratoires publics ou privés. 


\section{Biophysical forces rewire cell metabolism to guide microtubule-dependent cell mechanics}

Stephanie Torrino ${ }^{1 \$}$, Stephane Audebert ${ }^{2}$, llyes Belhadj ${ }^{1}$, Caroline Lacoux ${ }^{1}$, Sabrina Pisano ${ }^{3}$ Sophie Abélanet ${ }^{1}$, Frederic Brau ${ }^{1}$, Stephen Y. Chan ${ }^{4}$, Bernard Mari ${ }^{1}$, William M Oldham ${ }^{5}$, and Thomas Bertero ${ }^{1 \$}$

(1) Université Côte d'Azur, CNRS, IPMC, Valbonne, France

(2) Aix-Marseille Univ, INSERM, CNRS, Institut Paoli-Calmettes, CRCM, Marseille, France

(3) Université Côte d'Azur, CNRS, INSERM, IRCAN, Nice, France

(4) Center for Pulmonary Vascular Biology and Medicine, Pittsburgh Heart, Lung, Blood, and Vascular Medicine Institute, Division of Cardiology, Department of Medicine, University of Pittsburgh School of Medicine and University of Pittsburgh Medical Center, Pittsburgh, PA, USA

(5) Division of Pulmonary and Critical Care Medicine, Department of Medicine, Brigham and Women's Hospital, Harvard Medical School, Boston, MA USA

\$Corresponding Authors:

Thomas Bertero, Ph.D.

Université Côte d'Azur

Institute of Molecular and Cellular Pharmacology

CNRS UMR 7275

660 , route des Lucioles, Sophia Antipolis,

06560 Valbonne, France

Tel : +33493957719

Fax : +33493957708

Email: thomas.bertero@univ-cotedazur.fr

and

Stephanie Torrino, PhD, Université Côte d'Azur

Institute of Molecular and Cellular Pharmacology

CNRS UMR 7275

660 , route des Lucioles, Sophia Antipolis, 06560 Valbonne, France

Tel : +33493957719

Fax : +33493957708

Email: stephanie.torrino@univ-cotedazur.fr 


\begin{abstract}
Mechanical signals regulate cell shape and influence cell metabolism and behavior. Cells withstand external forces by adjusting the stiffness of its cytoskeleton. Microtubules (MTs) act as compression-bearing elements in response to mechanical cues. Therefore, MT dynamics affect cell mechanics. Yet, how mechanical loads control MT dynamics to adjust cell mechanics to its locally constrained environment has remained unclear. Here, we show that mechanical forces rewire glutamine metabolism to promote MT glutamylation and force cell mechanics, thereby modulating mechanodependent cell functions. Pharmacologic inhibition of glutamine metabolism decreased MT glutamylation and affected their mechanical stabilization. Similarly, depletion of the tubulin glutamylase TTLL4 or overexpression of tubulin mutants lacking glutamylation site(s) increased MT dynamics, cell compliance and contractility, and thereby impacted cell spreading, proliferation and migration. Together our results indicate that mechanical cues sustain cell mechanics through glutaminolysis-dependent MT glutamylation, linking cell metabolism to MT dynamics and cell mechanics. Furthermore, our results decipher part of the enigmatic tubulin code that coordinates the fine tunable properties of MT mechanics, allowing cells to adjust the stiffness of their cytoskeleton to the mechanical loads of their environment.
\end{abstract}




\section{Main}

Fundamental aspects of cell behavior in living organisms-morphogenesis, collective migration and self-organization-are emergent properties of cells interconnected within a tissue network. Understanding the spatiotemporal control of cell behavior thus requires incorporation of information on how structural and architectural complexity of tissues is transmitted to their constituent cells ${ }^{1}$. Mechanotransduction enables cells to sense and adapt to external forces ${ }^{2}$. This mechanical response of cells involves the rapid remodeling of their cytoskeleton and regulates their metabolic states, which are dynamically transited to match energetic and biosynthetic requirements ${ }^{3-6}$. While, major emphasis in the mechanotransduction field has been placed on actin, the dynamics of microtubules (MTs) in response to mechanical cues suggests an equally important role for tubulin?

MTs are long, stiff polymers of $\alpha \beta$-tubulin that are structurally and functionally important components of the eukaryotic cell cytoskeleton, forming the mitotic spindle and the axonemes of cilia and flagella and serving as tracks for intracellular trafficking ${ }^{8}$. Yet, implications of MTs in the mechanotransduction processes are only emerging, and how MT dynamics affect mechanotransduction remains elusive.

To determine whether mechanical cues conveyed by extracellular matrix (ECM) stiffness modulate MT dynamics, we performed fluorescence recovery after photobleaching experiments (FRAP, Figure 1a and Extended Figure 1a) and monitored growing microtubule plus ends (EB1-EGFP time laps imaged, Figure 1b) on HeLa cells cultivated on a gradient of matrix stiffness. ECM stiffening increased the diffusion rate and decreased the mobile fraction of tubulin (Figure 1a an Extended Figure 1a), while decreased MT growth rate (Figure 1b). Together, these results indicate that ECM stiffening stabilize MT. Consistent with previously published results ${ }^{7,9}$, decreasing MT dynamics via taxol decreased cell contractility, while MT destabilization by nocodazole increased cell contractility, as measured by traction force microscopy (Extended figure 1b). Thus, ECM mechanical cues influence cell mechanics through MT dynamics.

MTs posttranslational modifications (PTMs) have been previously shown to modulate MT persistence ${ }^{10-12}$. Tubulin glutamylation has been reported to control MT severing ${ }^{13}$. Thus, we investigated whether mechanical forces modulate MT glutamylation (Figure 1c-d and Extended figure 1c-h). As quantified by immunoblotting and immunofluorescence, ECM stiffening (Figure 1c and Extended figure 1f), osmotic shock (Figure 1d and Extended figure 1h), and circular shear stress (Extended figure 1c) independently promoted MT glutamylation. Importantly, mechano-induced MT glutamylation was also observed in a breast 
cancer cell line and primary cells (Extended figure 1d-e). Furthermore, and consistent with previously published results ${ }^{14-17}$, upon mechanical stresses the MT lattice was robustly reorganized (Figure 1e-f and Extended figure 1f-h). More specifically, mechanical forces switched MT organization from a net-like phenotype to alignment via cortical arrays. Thus, mechanical cues increase MT glutamylation and reorganize the MT lattice.

Upon mechanical stress, the large increase of MT glutamylation is likely to require the mobilization of an important intracellular pool of glutamate, especially to ensure the persistence of the phenotype. Recently, we reported that mechanical cues promote glutamine catabolism, a process --mediated by the glutaminase (GLS) to sustain the metabolic needs of mechanoactivated cells $\mathbf{s}^{3,5}$. Thus, we hypothesized that mechanical loads increase glutamine uptake and catabolism to fuel the intracellular pool of glutamate required for MT glutamylation. Consistent with our hypothesis, steady state metabolomics profiles of HeLa cells indicated that both ECM stiffening (Extended Figure 2a) and osmotic shock (Extended Figure 2b) promote substantial global alterations of metabolism (Extended Figure 2a-d). Steady state levels of 33 metabolites highly enriched in pathways related to amino acid metabolism (aspartate, glutamate, arginine and proline) were significantly changed by both ECM stiffening and osmotic shock (Figure 2a-b). These analyses revealed a significant increase in the intracellular glutamate/glutamine ratio (Extended Figure 2e-f), while HeLa cells increased their rate of glutamine uptake upon matrix stiffening (Extended figure $\mathbf{2 g}$ ). Importantly, increased GLS expression (Extended figure 2h) and activity (Extended figure 2i) was observed in cells cultivated on stiff matrix. Taken together, these results support the notion that glutamine uptake and catabolism regulates the level of intracellular pool of glutamate in HeLa cells to sustain MT glutamylation under mechanical stresses.

To investigate whether the level of intracellular pool of glutamate is key to promote MT glutamylation, SLC1A3 overexpressing cells were cultivated on soft substrate in DMEM high glucose, $10 \%$ serum, $2 \mathrm{mM}$ glutamine and exposed for five minutes to various concentration of glutamate. Increased extracellular glutamate concentration increased intracellular glutamate (Extended figure 2j) and MT glutamylation (Figure 2c) indicating that, intracellular glutamate levels control MT glutamylation.

We next cultivated HeLa cells on soft vs. stiff substrate and exposed to $200 \mathrm{mCi} / \mathrm{mL}$ of ${ }^{3} \mathrm{H}$ glutamine for 2 hours in presence of cycloheximide -- a translational elongation inhibitor. As revealed by scintigraphy, increased ${ }^{3} \mathrm{H}$ incorporation in purified MT was observed in cells plated on stiff substrate, suggesting that glutamine support MT glutamylation. Then we investigated whether either pharmacological inhibition of GLS -- BPTES [bis-2-(5- 
phenylacetamido-1,3,4-thiadiazol-2-yl)ethyl sulphide] or CB839, or genetic inhibition of GLS (siGLS) impacted MT glutamylation.Inhibition of GLS using the two independent approaches blunted stiffness-induced glutamine catabolism, as quantified by LC-MS (Extended figure 3). and strongly decreased MTs glutamylation, as quantified by immunoblot (Figure $\mathbf{2 e}$ and Extended Figure 4a-c) and proteomic analyses of purified MT (Figure 2f). Strikingly, upon stiff matrix (50kPa), the GLS inhibitor-dependent decrease of MT glutamylation was associated with reorganization of the MTs networks to a net-like phenotype (Extended Figure 4d-e), phenocopying the observed events in cells cultivated on soft matrix (1kPa; Figure 1d-e). Importantly, both MT glutamylation (Figure 2e and Extended Figure 4c) and MT alignment (Extended Figure 4d-e) were rescued by glutamate supplementation.

To definitively establish the critical role of glutamine-GLS-glutamate axis for MT glutamylation, we performed ${ }^{13} \mathrm{C}_{5}$-glutamine tracing experiments coupled with proteomic analyses of purified MTs (Figure 2g). Cells were cultivated on soft or stiff substrate and exposed to $2 \mathrm{mM}^{13} \mathrm{C}_{5}$ glutamine for two hours in presence of cycloheximide. Increased ${ }^{13} \mathrm{C}$-glutamate incorporation on both $\alpha$-tubulin and $\beta$-tubulin $\mathrm{C}$-terminal tails was observed in cells cultivated on stiff substrate. Importantly, CB839 treatment abolished MT new glutamylation.

We next investigated whether GLS-dependent MT glutamylation modulates MT dynamics. On stiff matrix (50kPa), GLS inhibition increased MT growth rate (Figure $\mathbf{2 h}$ ) and decreased tubulin diffusion rate while increasing the mobile fraction (Figure 2i). Importantly, glutamate supplementation rescued MT stability (Figure $\mathbf{2 h}$-i). Thus, decreasing MT glutamylation in cells cultivated on stiff substrate decreased their stability. Taken together, these results demonstrate that mechanical stresses rewire cell glutamine metabolism to sustain the glutamate production required for MT glutamylation-dependent stabilization.

To gain insight into the molecular mechanisms associated with this process, we next sought to identify the enzymes involved in tubulin glutamylation following mechanical stress. MT glutamylation is a dynamic process that occurs through a balance between glutamate addition by a family of glutamylase enzymes (TTLLs) ${ }^{18}$, and glutamate removal by a family of deglutamylase enzymes (CCPs) ${ }^{19,20}$. We performed siRNA screening to identify TTLL and CCP enzyme family members responsible for MT glutamylation in response to mechanical stress (Figure 3 and Extended figure 5). Knockdown efficiency was first validated by RT-qPCR (Extended figure 5a). We found that TTLL4, and, to a lesser extent, TTLL5 and TTLL9 depletion significantly decreased MT glutamylation (Figure 3a), while CCP5 was the sole deglutamylase where knockdown robustly increased MT glutamylation (Extended Figure 5b). 
These results were confirmed using three distinct single siRNAs directed against TTLL4 and CCP5 (Extended figure $5 c-f)$.

We next investigated whether modulating these enzymes affected the MT lattice. Consistent with our immunoblot results, confocal microscopy confirmed that siRNA knockdown of TTLL4 decreased tubulin glutamylation (Figure 3b). Strikingly, decreased MT glutamylation in cell cultivated on stiff matrix (50kPa) reorganized the MT networks to a net-like phenotype (Figure $\mathbf{3 b}$ and Extended figure $\mathbf{5 g}$ ), as observed in cell cultivated on soft matrix ( $1 \mathrm{kPa})$. Conversely siRNA knockdown of CCP5 in cells cultivated on soft matrix $(1 \mathrm{kPa})$ increased MT glutamylation (Extended Figure 5h) and aligned MTs (Extended figure 5i) as observed in cell cultivated on stiff matrix. Then, we monitored growing microtubule plus ends and performed FRAP experiments, thus finding that modulation of MT glutamylation impacted MT dynamics in cells (Figure 3c-d and Extended figure 6a-b). Altogether, we establish that in response to matrix stiffening, MT glutamylation is orchestrated by TTLL4 and CCP5 which ensure MT organization. Forced MT glutamylation in cells cultivated on soft matrix is sufficient to induce a stiff-like MT lattice phenotype, while MT glutamylation on stiff matrix is necessary to sustain the phenotype. Thus, MT glutamylation is necessary and sufficient to organize the MT lattice.

We next interrogated the importance of MT glutamylation and subsequent MT lattice organization on cell mechanical properties and associated-cellular functions (Figure $\mathbf{3 e}-\mathbf{h}$, Extended figure 6 and Extended Figure 7). To investigate whether MT glutamylation impacts cell elasticity, cell contractility and cell membrane tension, cells were plated on either soft (1kPa; siCCP5) or stiff matrix (50kPa; siTTLL4), and we performed atomic force microscopy (Figure 3e) and traction force microscopy experiments (Figure $3 \mathrm{f}$ and Extended figure 6c). We observed increased cell compliance (Figure $\mathbf{3 e}$ ) and increased cell traction (Figure $\mathbf{3 f}$ ) in TTLL4-depleted cells, while converse observations were detected in CCP5-depleted cells (Extended figure 6c), demonstrating that MT (de)glutamylation affects cell mechanical properties.

On the basis of these findings, we investigated whether tubulin glutamylation may also impact cell functions dependent upon biophysical mechanics such as cellular shape, adhesion, proliferation and migration. Using a similar experimental design, we found that forced tubulin deglutamylation by knocking down TTLL4 (siTTLL4), TTLL5 (siTTLL5) or TTLL9 (siTTLL9) on stiff matrix (50kPa) increased the cell circularity index (Figure $\mathbf{3 g}$ and Extended Figure 7) while decreased both cell proliferation (Extended Figure 6e and Extended Figure 7) and migration (Extended Figure 6i and Extended Figure 7). Conversely, forced tubulin glutamylation on soft substrate $(1 \mathrm{kPa})$ by knocking down CCP5 (siCCP5) decreased the cell 
circularity index (Extended Figure 6f), increased cell proliferation (Extended Figure 6h), and decreased cell migration (Extended Figure 6i). Modulation of MT glutamylation had no effect on cell adhesion (Extended figure $\mathbf{6 g}-\mathbf{h}$ ). Together, our results indicate that (de)glutamylation enzymes play a central role on cell mechanical properties and dependent cell functions.

To demonstrate the central role of tubulin (de)glutamylation on MT dynamics, cell mechanics, and mechanodependent cell functions, we investigated MT lattice organization, MT dynamics, and cell mechanics of HeLa cells overexpressing tubulin mutants lacking glutamylation site(s) (Figure 4 and Extended Figure 8). As quantified by immunoblotting (Figure 4b) and immunofluorescence (Figure 4c) forced expression of either Tub $\Delta$ Cter (a tubulin lacking the eleven C-terminal amino acid) or Tub_E445D (a tubulin in which the glutamate at position 445 is mutated to aspartate ${ }^{26-29}$ ) decreased MT glutamylation. Consistent with our previous results, decreased MT glutamylation reorganized the MT lattice (Figure 4c and Extended Figure 8a), modulated MT dynamics (Figure 4d and Extended Figure 8b), increased cell compliance and cell contractility (Figure 4e-f), increased cell circularity (Figure $\mathbf{4 g}$ ) and decreased both cell proliferation and migration (Extended Figure 8c-d). Together, our results underline the central role of tubulin (de)glutamylation on cell mechanical properties and cell behavior, including migration and proliferation.

Overall, we show here that the mechano-dependent metabolic rewiring of cells represents a critical mediator of MT mechanics. While previous studies demonstrated the role of MT dynamics in cell mechanics ${ }^{7}$, the potential significance of MT PTMs and their associated dependence on cell metabolism has not been described previously. We demonstrate that mechanical cues precisely coordinate cell metabolism and MT glutamylation to stabilize the MT lattice in order to adjust cell cytoskeleton stiffness and adapt to mechanical load. Although several mechanotransduction pathways have been uncovered ${ }^{2,30-33}$, the molecular mechanisms identified so far have mainly addressed the perception of stress intensity and not the direction of the mechanical information. Here, by uncovering MTs glutamylation as a necessary and sufficient PTM to reorganize the MTs lattice under mechanical stresses and to increase MTs persistence, we point out MTs as ideal anisotropic sensors to perceive the directions of cell-scale mechanical signals ${ }^{34,35}$. Yet, whether other partners are needed for MTs to sense tension remain to be addressed, and further studies should evaluate the importance of cytoskeletal crosstalk ${ }^{22}$ in orchestrating cell mechanics in a precise and highly adaptable manner.

Our study also uncovered the PTM enzymes involved in this specific pathway. Previous studies linking MT dynamics to cell mechanics mostly relied on the use of MT-targeting agents, $7,9,36$ 
such as taxol and nocodazole that markedly disrupt MT dynamics and profoundly disorganized the MT lattice. Here, we identify the specific enzymes involved in tubulin glutamylation in response to mechanical cues. By identifying TTLL4 and CCP5 as crucial mediators of this process, we unveil the fine tunable properties of MT mechanics allowing cells to adjust the stiffness of their cytoskeleton to the mechanical loads of their environment. Because TTLL4 has recently been shown to glutamylate several other substrates ${ }^{37-39}$, we investigated the cell mechanical properties of cells expressing tubulin mutants, demonstrating that TTLL4-regulated cell mechanics strictly rely on MT glutamylation. Yet, the true breadth of influence of MT PTMs on cell mechanics and mechanodependent cellular function may involve additional molecular components. While here we reported that MT glutamylation stabilize MT, our results showing that siRNA knockdown of TTLL13 increased MT glutamylation (Figure 3a) and siRNA knockdown of CCP4 decreased MT glutamylation (Extended Figure 5b) suggest a previously reported biphasic dependence of MT stability on glutamylation ${ }^{13}$. Further studies are necessary to investigate the physiological relevance of this mechano-induced feedback loop. In addition, while we demonstrated the importance of MT glutamylation on several cell mechanodependent cell functions such as proliferation and migration in 2 dimensional cell culture, further studies are necessary to decipher the role of MT glutamylation in 3 dimensional space, thereby refining the molecular codes embedded in this complex network of post-translationally modified tubulin isoforms. 


\section{Methods \\ Reagents and antibodies}

Nocodazole (487928), Taxol (T7402), Cycloheximide (01810), BPTES (SML0601) were purchased from Sigma-Aldric and were used at the final concentration of $10 \mu \mathrm{M}$. Glutamate (5mM) was purchased from Gibco. CB839 (S76655) was purchased from Selleck Chemicals and used at the final concentration of $1 \mu \mathrm{M}$. MES buffer (15424169), GTP (1mM; 15255116), DTT (10699530), Protease and Phosphatase Inhibitor (15662249) were purchased from Thermo Fisher Scientific. The following commercially available antibodies were used for western blotting and immunofluorescence: - mouse monoclonal antibodies against Glu-Tubulin (CliniSciences, AG-20B-0020-C100), Tubulin (Santa Cruz Biotechnology, sc-398937), Hsp90 (Santa Cruz Biotechnology, sc-69703), Hsp60 (Santa Cruz Biotechnology, sc-271215); - rabbit polyclonal antibodies against Tubulin (Sigma-Aldrich, SAB4500087), TTLL4 (Bio-Techne, NBP1-81535), CCP5 (Abcam, ab170541), GLS (Abcam, ab93434). HRP-conjugated donkey anti-mouse IgG (715-035-150) and HRP-conjugated anti-mouse IgG (711-035-152) were purchased from Jackson ImmunoResearch Laboratories.

\section{Cell culture}

HeLa cells and MDA-MB-468 cells were purchased from the American Type Culture Collection (ATCC). Cells used in this study were within 20 passages after thawing and were cultured $\left(37^{\circ} \mathrm{C}, 5 \% \mathrm{CO}_{2}\right)$ in Dulbecco's Modified Eagle's Medium (DMEM, Gibco) supplemented with 10\% fetal bovine serum (Gibco), Glutamine (2mM, Gibco) and Penicillin/Streptomycin (1\%, Gibco). Primary human pulmonary arterial smooth muscle cells (PASMCs) were cultured in SmGM-2 cell culture media (Lonza), and experiments were performed at passages 3 to 9. For the studies dependent on matrix stiffness, collagen-coated hydrogel pre-plated in culture wells (Matrigen) was generated from a mix of acrylamide and bis-acrylamide coated with collagen. Cells were cultured, passaged, and harvested while on top of the hydrogel, using standard cell culture techniques.

\section{SiRNA and plasmid transfection}

Cells were plated on collagen-coated plastic $(50 \mu \mathrm{g} / \mathrm{mL})$ and transfected $24 \mathrm{~h}$ later at $70-80 \%$ confluence using siRNA $(25 \mathrm{nM})$ and Lipofectamine 2000 reagent (Life Technologies), according to the manufacturers' instructions. Eight hours after transfection, cells were trypsinized and re-plated on hydrogel. The PMXS retroviral vector containing the coding sequence for SLC1A3 was purchased (Addgene; Plasmid \#7287340). The mammalian expression vector containing the coding sequence for EB1-2xEGFP was purchased (Addgene; Plasmid \# 3782741) The pShuttle mCherry-Tubulin adenoviral vector (Tub-WT) was purchased (Addgene; Plasmid \# 2676842). Tubulin mutants have been generated using the pShuttle 
mCherry-Tubulin plasmid following recommendations of the Q5 site directed-mutagenesis kit from New England Biolab (\#E0554). Oligos Forward pShut: GCGCCGCTCGAGCCTAAG and

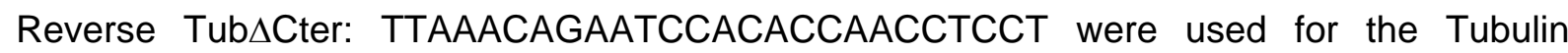
deletion mutant (TubACter) and oligos Forward pShut: GCGCCGCTCGAGCCTAAG and Reverse TubE445D: TTAGTATTCCTCTCCTTCATCСTCACСCT were used for the Tubulin Substitution mutant (TUBE445D). pShuttle mCherry-Tubulin mutations were verified by sequencing using oligos pASV40: GAAATTTGTGATGCTATTGC and SeqTub: CAGGTCTCCACCAGGCACCA.

Forty-eight after transfection cells were harvest for analysis. siRNA ON-TARGETplus Human or Non-Targeting Control siRNAs (D-001810-01) were purchased from Horizon Discovery Ltd). Sequences of SMARTpool or single siRNA ON-TARGETplus Human are provided in the Table:

\begin{tabular}{|c|c|c|c|}
\hline & \begin{tabular}{|l|} 
Pool \\
Catalog \\
Number \\
\end{tabular} & Sequence & Single Catalog Number \\
\hline \multirow[t]{4}{*}{ GLS } & $\begin{array}{l}\text { L-004548- } \\
01\end{array}$ & CCUGAAGCAGUUCGAAAUA & $\mathrm{J}-004548-09$ \\
\hline & & CUGAAUAUGUGCAUCGAUA & $\mathrm{J}-004548-10$ \\
\hline & & AGAAAGUGGAGAUCGAAAU & J-004548-11 \\
\hline & & GCACAGACAUGGUUGGUAU & $\mathrm{J}-004548-12$ \\
\hline \multirow[t]{4}{*}{ TTLL4 } & \begin{tabular}{|l} 
L-020210- \\
01
\end{tabular} & GUGGAAACCUCCUGCGGUA & $\mathrm{J}-020210-09$ \\
\hline & & ACGCCAAGCUCCUGCGCAA & J-020210-10 \\
\hline & & ACAUCAUGCUAGACGAAAA & \begin{tabular}{|l|}
$\mathrm{J}-020210-11$ \\
\end{tabular} \\
\hline & & UCUCAAAGGAUGACGUGAU & J-020210-12 \\
\hline \multirow[t]{4}{*}{ CCP5 } & $\begin{array}{l}\text { L-009468- } \\
00\end{array}$ & GUGUAGAUCUGCUGACGAU & J-009468-05 \\
\hline & & GAGUGGCGUUGCUUACUAU & J-009468-06 \\
\hline & & GAAUCUUUGUCCAGUGAUG & J-009468-07 \\
\hline & & UGACAGGCAUAACGCUGAA & J-009468-08 \\
\hline \multirow[t]{4}{*}{ TTLL5 } & $\begin{array}{l}\text { L-015406- } \\
01\end{array}$ & GAGUAAUUGGAGAACGUUA & \\
\hline & & CAGCUGAGUACGCGGAAUU & \\
\hline & & GGUUUGCAACUGUGCGAUA & \\
\hline & & GGUCCUACCUCGAGCAUAA & \\
\hline \multirow[t]{4}{*}{ TTLL7 } & \begin{tabular}{|l} 
L-018159- \\
02
\end{tabular} & GAACAUGAAAAUCGACAUA & \\
\hline & & GAAAGAGAGACUCGCUCAA & \\
\hline & & GCUAAGUUUUGGAGUGAUA & \\
\hline & & CUGCAUGCCUAUCGAAUGU & \\
\hline \multirow[t]{4}{*}{ TTLL1 } & $\begin{array}{l}\text { L-009556- } \\
01\end{array}$ & GUGUGCAAACCAUCCGAAA & \\
\hline & & ACAUCAUCAUCGACGACAA & \\
\hline & & GGAAGUUCGACCUGCGCUU & \\
\hline & & GCAAGCUGUUCGACGAGAU & \\
\hline
\end{tabular}




\begin{tabular}{|c|c|c|}
\hline \multirow[t]{4}{*}{ TTLL6 } & \begin{tabular}{|l} 
L-018230- \\
01
\end{tabular} & GCACUUAACCUCCGUAGAA \\
\hline & & GGAAUCGGCAGGCGAGCAA \\
\hline & & GGAGGGAUAUUGAGGACGU \\
\hline & & AAACAGAGGUGAGGCGAGA \\
\hline \multirow[t]{4}{*}{ TTLL9 } & \begin{tabular}{|l} 
L-024287- \\
01
\end{tabular} & ACUAUGUGGCUCAGCGUUA \\
\hline & & GCUUCGAGCUGUACGGCUA \\
\hline & & GUAGAGGAGUUUCGCAAAA \\
\hline & & UGGAUGAACAUGUGCGGAU \\
\hline \multirow[t]{4}{*}{ TTLL11 } & $\begin{array}{l}\text { L-016360- } \\
01\end{array}$ & UGACGGAGAUGGUGCGUAA \\
\hline & & GAGUUUCAUUUCACGACAA \\
\hline & & UCAAAUGGUGAAAGACGAU \\
\hline & & GGAUUCUGCCUGACGAGUU \\
\hline \multirow[t]{4}{*}{ TTLL13 } & \begin{tabular}{|l} 
L-033428- \\
01
\end{tabular} & CCUACGGUCGUCAGCGAAA \\
\hline & & AGUUGACACAGGCGACUUA \\
\hline & & GAGGAUAAGCGGCGAGUCA \\
\hline & & AGAGGAAGCUGUCGACACU \\
\hline \multirow[t]{4}{*}{ CCP1 } & $\begin{array}{l}\text { L-014059- } \\
00\end{array}$ & UAUCAUAGAUCGUGUGGUA \\
\hline & & GCUUAUCACUAUCCAUAUA \\
\hline & & AUACAAGGGUUUACAGAUU \\
\hline & & UGAAAGGAACGUUGGAAUA \\
\hline \multirow[t]{4}{*}{ CCP2 } & $\begin{array}{l}\text { L-012937- } \\
00\end{array}$ & GCACACUUCUACCCAUAUA \\
\hline & & UGGACAAGAUGUAGAUUUA \\
\hline & & GAACUCACCUUGCGAACUG \\
\hline & & GAUAAUACUCUACUGUUUG \\
\hline \multirow[t]{4}{*}{ CCP3 } & \begin{tabular}{|l} 
L-025456- \\
01
\end{tabular} & GCACAGUUGCUUCGGGACA \\
\hline & & UAAUAUGCGAGCAGGAAUA \\
\hline & & GAACAGGAAGGGUGGUAAU \\
\hline & & UGAAAGGCUUCCUAGAUUA \\
\hline \multirow[t]{4}{*}{$\mathrm{CCP} 4$} & $\begin{array}{l}\text { L-017061- } \\
02\end{array}$ & AGCCUAUGUUGGAACGAAA \\
\hline & & ACUUGGAAACAGACGUGAA \\
\hline & & GGUGAUCACUGCUCGAGUU \\
\hline & & AAGCCAUCCAAGUGCGUGA \\
\hline \multirow[t]{4}{*}{ CCP6 } & \begin{tabular}{|l} 
L-014994- \\
02
\end{tabular} & GAGUCUACCUGGGCAAUUA \\
\hline & & GGUGUUCUCUGAUGGGAUU \\
\hline & & GCCAAGGGAUCAUUGACUU \\
\hline & & AGAGUGUGCAACAACGAAA \\
\hline \multirow[t]{3}{*}{ ARHGEF2 } & \begin{tabular}{|l} 
L-009883- \\
00
\end{tabular} & GAAUUAAGAUGGAGUUGCA \\
\hline & & GUGCGGAGCAGAUGUGUAA \\
\hline & & GAAGGUAGCAGCCGUCUGU \\
\hline
\end{tabular}




\section{CCACGGAACUGGCAUUACU}

\section{Immunofluorescence}

Cells were fixed with PBS/PFA 4\% for 10 min and permeabilized with PBS/Triton 100X 0.2\% for 5 min. After blocking with PBS/Triton/BSA $0.2 \%$ for $1 \mathrm{~h}$, the cells were then incubated with primary antibodies (1/100) at room temperature for $1 \mathrm{~h}$. Secondary antibodies coupled with Alexa-594 and/or Alexa-488 (A-11012, A-11001, Life technologies) were used at 1/500 for confocal imaging, while Alexa 594 and Star Red (Abberior) were used at 1/100 for STED imaging. Nuclei were counterstained with DAPI (Sigma-Aldrich). Images were obtained using a Laser Scanning confocal microscope (LSM780, Carl Zeiss) or through STED microscopy (TCS SP8 3X (Leica Microsystems), equipped with a pulsed white light laser to excite the Alexa594 at 561nm and the StarRed at 633nm. Both staining were depleted with the $775 \mathrm{~nm}$ pulsed laser (45\% power for both, 4 and 6 accumulations respectively). All images were acquired at $700 \mathrm{~Hz}$ through a Plan Apochromat 93x/1.3 NA Glycerol objective using the LAS $X$ software (Leica Microsystems). All STED images had a 17-nm pixel size. All images were deconvoluted with Huygens Professional (version 18.10, Scientific Volume Imaging), using the CMLE algorithm (SNR :14, 40 iterations).

\section{Hypo-osmotic shock}

Hypo-osmotic shock was performed by diluting growth medium with deionized water (1:9 dilution for 30 mOsm hypo-osmotic shock) for the indicated time.

\section{Shear stress}

Cells were exposed to orbital shear stress with an orbital shaker ( 7 dynes $\left./ \mathrm{cm}^{2}\right)$ for the indicated time.

\section{Microtubule Purification}

Microtubules were purified using the Taxol-Based Isolation of Tubulin from Cell as described ${ }^{43}$. Briefly, Adherent cells are washed and scraped in $1 \mathrm{ml}$ of PBS. After centrifugation at $1200 \times \mathrm{g}$, cells are resuspended in MME buffer. The cell suspension is sonicated with a microtip probe seven times for $30 \mathrm{~s}$ with $30 \mathrm{~s}$ rest intervals on melted ice. The cell lysate is spun at $120,000 \times \mathrm{g}$ (Beckman TL100 centrifuge) for $1 \mathrm{~h}$ at $4^{\circ} \mathrm{C}$. Cytosolic supernatants are incubated for $20 \mathrm{~min}$ at $37^{\circ} \mathrm{C}$ in the presence of $10 \mu \mathrm{M} \mathrm{Taxol}, 5 \%$ sucrose and $1 \mathrm{mM}$ GTP. Samples are centrifuged at $80,000 \times \mathrm{g}$ for $30 \mathrm{~min}$ at $37^{\circ} \mathrm{C}$. Pellets are washed with $0.1 \mathrm{ml}$ of warm MME buffer and resuspended in $\mathrm{MME}$ buffer containing $0.35 \mathrm{MNaCl}$ and $10 \mu \mathrm{M}$ Taxol on ice. After centrifugation at $80,000 \times \mathrm{g}$ for $30 \mathrm{~min}$ at $37^{\circ} \mathrm{C}$, microtubule pellets are frozen on dry ice and kept at $-70^{\circ} \mathrm{C}$ until their use. 


\section{Radioactivity}

Posttranslational labeling was performed by incubating cells in normal growth medium containing $400 \mathrm{mCi} / \mathrm{mL}\left[{ }^{3} \mathrm{H}\right]$ glutamine (PerkinElmer, 30-60 Ci/mmol) in the presence of (100 $\mu \mathrm{g} / \mathrm{ml}$ ) cycloheximide, a strong inhibitor of protein synthesis. These conditions resulted in the specific labeling of the polyglutamyl lateral chain (Eddé et al., 1992; Audebert et al., 1993). Purified microtubule from triplicate samples of Hela cells cultured under soft $(1 \mathrm{kPa})$ or stiff matrix ( $50 \mathrm{kPa})$ for 48 hours were eluted by boiling in $2 \mathrm{X}$ sample buffer at $95^{\circ} \mathrm{C}$ for $10 \mathrm{~min}$. The eluted fractions were analyzed by after SDS-PAGE. The radioactivity resulting from $[3 \mathrm{H}]$ glutamine incorporation into tubulin was determined. Proteins were transferred onto nitrocellulose and the membrane was stained with Ponceau Red. Tubulin bands were then cut out and processed directly for liquid scintillation counting.

\section{Proteomic and stable carbon isotope proteomic analysis}

Purified microtubule from triplicate samples of Hela cells cultured under soft $(1 \mathrm{kPa})$ or stiff matrix $(50 \mathrm{kPa})$ for 48 hours and treated with CB839 for 24 hours were analysed. To trace microtubule neo-glutamylation, cells were cultivated in DMEM containing 10\% FBS, 4.5g. $\mathrm{L}^{-1}$ glucose, $2 \mathrm{mM}$ glutamine and then transferred into glutamine free (with $4.5 \mathrm{~g} . \mathrm{L}^{-1}$ glucose) DMEM containing $10 \%$ dialyzed FBS and supplemented with $2 \mathrm{mM}{ }^{13} \mathrm{C}_{5}$-glutamine for 2 hours in presence of $(100 \mu \mathrm{g} / \mathrm{ml})$ cycloheximide. Microtubules were purified according to the taxolbased purification procedure. Microtubule pellet were homogenized in $100 \mu \mathrm{l} 50 \mathrm{mM}$ ammonium bicarbonate and digested with thermolysin (Promega Corporation) at $65^{\circ} \mathrm{C}$ for $2 \mathrm{~h}$ and at $37^{\circ} \mathrm{C}$ for an additional incubation time of $16 \mathrm{~h}$. Peptides were further dried under speed vacuum concentrator and resuspended in $20 \mu \mathrm{l}$ Water/0.1\% TFA (trifluoracetic Acid) for liquid chromatography (LC)-tandem mass spectrometry (MS/MS) analysis using an Orbitrap Fusion Lumos Tribrid mass spectrometer in-line with an Ultimate 3000 RSLCnano chromatography system (ThermoFisher Scientific). First, peptides $(2 \mu \mathrm{l}, 10 \%$ of whole sample) were concentrated and purified on a pre-column from Dionex (C18 PepMap100, $2 \mathrm{~cm} \times 100 \mu \mathrm{m}$ I.D, $100 \AA$ pore size, $5 \mu \mathrm{m}$ particle size) in solvent $\mathrm{A}(0.1 \%$ formic acid in $2 \%$ acetonitrile). In the second step, peptides were separated on a reverse phase LC EASY-Spray C18 column from Dionex (PepMap RSLC C18, 50cm $\times 75 \mu \mathrm{m}$ I.D, $100 \AA$ pore size, $2 \mu \mathrm{m}$ particle size) at $300 \mathrm{~nL} / \mathrm{min}$ flow rate and $40^{\circ} \mathrm{C}$. After column equilibration using $4 \%$ of solvent $\mathrm{B}(20 \%$ water $80 \%$ acetonitrile $-0.1 \%$ formic acid), peptides were eluted from the analytical column by a twostep linear gradient (4-20\% acetonitrile/ $\mathrm{H}_{2} \mathrm{O} ; 0.1 \%$ formic acid for $90 \mathrm{~min}$ and $20-45 \%$ acetonitrile/ $\mathrm{H}_{2} \mathrm{O} ; 0.1 \%$ formic acid for $20 \mathrm{~min}$ ). For peptide ionization in the EASY-Spray nanosource, spray voltage was set at $2.2 \mathrm{kV}$ and the capillary temperature at $275^{\circ} \mathrm{C}$. The Advanced Peak Determination (APD) algorithm was used for real time determination of 
charges states and monoisotopic peaks in complex MS spectra. The mass spectrometer was used in data dependent mode to switch consistently between MS and MS/MS. Time between Masters Scans was set to 3 seconds. MS spectra were acquired in the range $\mathrm{m} / \mathrm{z}$ 400-1600 at a FWHM resolution of 120000 measured at $200 \mathrm{~m} / \mathrm{z}$. AGC target was set at $4.0 .10^{5}$ with a 50 ms maximum injection time. The most abundant precursor ions were selected and collision induced dissociation fragmentation at $35 \%$ was performed and analysed in the ion trap using the "Inject lons for All Available Parallelizable time" option with a dynamic maximum injection time. Charge state screening was enabled to include precursors with 2 and 7 charge states. Dynamic exclusion was enabled with a repeat count of 1 and duration of 60s.

Raw files generated from mass spectrometry analysis were processed with Proteome Discoverer 1.4 (Thermo fisher Scientific). This software was used to search data via in-house Mascot server (version 2.4.1; Matrix Science Inc., London, UK) against the human tubulin proteins (Uniprot accession number : P68371, Q13509, Q13885, P04350, Q9BUF5, Q3ZCM7, Q9H853, Q9H4B7 for beta-tubulin and P0DPH7, Q9BQE3, Q6PEY2, P68366, Q71U36, Q9NY65, A6NHL2, P68363 for the alpha-tubulin). For alpha-tubulin subunit, sequences lacking the last carboxy-terminal tyrosine residues or the penultimate glutamate were also manually added to the fasta file to mimic putative posttranslational removal of the last or two last amino acids respectively ${ }^{44,45}$. They were annoted PODPH7_Y and PODPH7_EY. To this fasta file, were added a subset of the swissprot human database corresponding to the 1159 first proteins among a total of 20,413 entries of the human SwissProt database (version 2019.11). Database search were done using the following settings: thermolysin cleavage before $\mathrm{L}, \mathrm{F}, \mathrm{V}, \mathrm{I}, \mathrm{A}$ or $\mathrm{M}$ amino acids with a maximum of 4 thermolysin miscleavage allowed, no static modifications. As glutamylation of tubulin is a complex modification with increasing length of glutamyl residues on the lateral chain of a glutamate residue of the main chain, we fixed parameters that will allow the identification of glutamyl chain bearing from 0 to 8 glutamyls units. As we were interested in the incorporation of neo-glutamylated residues, we looked for peptides that incorporated one heavy glutamyl ${ }^{13} \mathrm{Glu}$ group ${ }^{13} \mathrm{C}(5) \mathrm{H}(7) \mathrm{N} \mathrm{O}(3)$ ) in the modified chain. With these criteria, 8 dynamic modifications were used for database search:

$\begin{array}{lll}{ }^{13} \mathrm{Glu} & 134.059367 & { }^{13} \mathrm{C}(5) \mathrm{H}(7) \mathrm{N} \mathrm{O}(3) \\ \mathrm{Glu}^{13} \mathrm{Glu} & 263.101960 & { }^{13} \mathrm{C}(5) \mathrm{C}(5) \mathrm{H}(14) \mathrm{N}(2) \mathrm{O}(6) \\ \text { GluGlu}^{13} \mathrm{Glu} & 392.144554 & { }^{13} \mathrm{C}(5) \mathrm{C}(10) \mathrm{H}(21) \mathrm{N}(3) \mathrm{O}(9) \\ \text { GluGluGlu}{ }^{13} \mathrm{Glu} & 521.187147 & { }^{13} \mathrm{C}(5) \mathrm{C}(15) \mathrm{H}(28) \mathrm{N}(4) \mathrm{O}(12) \\ \text { GluGluGluGlu}{ }^{13} \mathrm{Glu} & 666.224654 & { }^{13} \mathrm{C}(5) \mathrm{C}(20) \mathrm{H}(35) \mathrm{N}(5) \mathrm{O}(16) \\ \text { GluGluGluGluGlu}{ }^{13} \mathrm{Glu} & 779.272333 & { }^{13} \mathrm{C}(5) \mathrm{C}(25) \mathrm{H}(42) \mathrm{N}(6) \mathrm{O}(18) \\ \text { GluGluGluGluGluGlu}{ }^{13} \mathrm{Glu} & 908.314926 & { }^{13} \mathrm{C}(5) \mathrm{C}(30) \mathrm{H}(49) \mathrm{N}(7) \mathrm{O}(21) \\ \text { GluGluGluGluGluGluGlu}{ }^{13} \text { Glu } & 1037.357519 & { }^{13} \mathrm{C}(5) \mathrm{C}(35) \mathrm{H}(56) \mathrm{N}(8) \mathrm{O}(24)\end{array}$

A peptide mass tolerance of $6 \mathrm{ppm}$ and a fragment mass tolerance of $0.2 \mathrm{Da}$ were allowed for search analysis. Only peptides with higher Mascot threshold (identity) were selected. False 
discovery rate was set to $1 \%$ for protein identification. For all experiments, the quantity of the glutamatylated C-terminal tubulins tail identified was normalized by the quantity of corresponding C-terminal tubulin tail identified. Number of PSM (Peptide Spectrum Matches) values from Proteome Discoverer results were used for spectral counting quantification. Peptides VDSVEGEGEEEGEEY, LEKDYEEVGVDSVEAE from alpha 1 and alpha 3d carboxy terminal tubulin sequences and peptides LVSEYQQYQDATAEEEEDEEYAEEE, from beta-8 tubulin isotype showed ${ }^{13} \mathrm{Glu}$ neo incorporation.

\section{Western blot assays}

Forty-eight hours after plaiting, cells were lysed in RIPA buffer (Pierce) or directly in Laemmli's buffer. After denaturation, protein lysates were resolved by SDS-PAGE and transferred onto a PVDF membrane (Millipore). Membranes were blocked with 2\% BSA in TBS tween20 0.1\% and incubated in the presence of the primary and then secondary antibodies. After washing, immunoreactive bands were visualized with ECL (Millipore) and analyzed on Fusion-FX Imager (Vilber). ImageJ software was used to quantify band intensity and the ratios of proteins of interest were normalized to Hsp90 (loading control). For the analysis, Glu-Tubulin levels were quantified by calculating the ratio between Glu-Tubulin and Tubulin, both normalized to Hsp90 signal as follows: (Glu-Tubulin /Hsp90Glu-Tubulin) / (Tubulin /Hsp90 Tubulin). Mean expression in controls was assigned a fold change of 1 , to which relevant samples were compared.

\section{RNA isolation, RT-PCR and q-PCR}

Total RNA was extracted by TRIzol reagent according to the manufacturer's instructions (Invitrogen). RNA quantity and quality were determined using NanoDrop ${ }^{\text {тм }}$ One Spectrophotometer (Thermo Scientific). One microgram of total RNA was reverse transcribed to generate cDNA (A3500, Promega). cDNA was amplified via fluorescently labeled Taqman primer sets using an Applied Biosystems 7900HT Fast Real Time PCR device. Fold change of RNA species was calculated using the formula $\left(2^{-\Delta \Delta c t}\right)$, normalized to RPLP0 expression. All real-time RT-PCR assays were performed in triplicate with three independent experiments. Primers are provided in Table:

\begin{tabular}{|l|l|}
\cline { 2 - 2 } \multicolumn{1}{c|}{} & Taqman Catalog Number \\
\hline RPLP0 & Hs99999902 \\
\hline TTLL1 & Hs00923132 \\
\hline TTLL4 & Hs01565335 \\
\hline TTLL5 & Hs00209404 \\
\hline TTLL6 & Hs00543401 \\
\hline TTLL7 & Hs01114458 \\
\hline
\end{tabular}




\begin{tabular}{|l|l|} 
TTLL9 & Hs01082287 \\
\hline TTLL11 & Hs00879398 \\
\hline TTLL13 & Hs01050281 \\
\hline CCP1 & Hs00999967 \\
\hline CCP4 & Hs00328701 \\
\hline CCP2 & Hs01050124 \\
\hline CCP3 & Hs01570549 \\
\hline CCP6 & Hs00901829 \\
\hline CCP5 & Hs00222447 \\
\hline
\end{tabular}

\section{Atomic force microscopy}

Cells were first washed twice with $3 \mathrm{ml}$ of Liebovitz's medium (Life Technologies) supplemented with heat-inactivated 10\% Fetal Bovine Serum (FBS), then covered with $3 \mathrm{ml}$ of the same medium. The mechanical properties of samples were studied using a BioScope Catalyst atomic force microscope (Bruker Nano Surfaces, Santa Barbara, CA, USA) equipped with a Nanoscope $V$ controller and coupled with an optical microscope (Leica DMI6000B, Leica Microsystems Ltd., UK). For each sample, at least 30 cells were analyzed using the "Point and Shoot" method, collecting at least 150 force-distance curves at just as many discrete points (on average 5 points for each cell in the perinuclear area). The experiments were performed using a probe with a borosilicate glass spherical tip ( $5 \mu \mathrm{m}$ diameter) and a cantilever with a nominal spring constant of $0.06 \mathrm{~N} / \mathrm{m}$ (Novascan Technologies, Ames, IA USA). After determining both the deflection sensitivity of the system in the Leibovitz's medium using a clean Willco Glass Bottom Dish and the spring constant of the cantilever by the thermal tune method, force-distance curves were collected on samples using a velocity of $2 \mu \mathrm{m} / \mathrm{s}$, in relative trigger mode and by setting the trigger threshold to $1 \mathrm{nN}$. The apparent Young's modulus was calculated using the NanoScope Analysis 1.80 software (Bruker Nano Surfaces, Santa Barbara, CA, USA) applying to the force curves, after the baseline correction, the Hertz spherical indentation model using a Poisson's ratio of 0.5 . Only the force curves having their maximum value at $1 \mathrm{nN}$ were considered for the analysis. For each force curve, the force fit boundaries to perform the fit were chosen between 50 and $250 \mathrm{pN}$ and only the apparent Young's modulus values corresponding to a fit with $R^{2}>0.80$ were accepted.

\section{Traction force microscopy}

Contractile forces exerted by cells on different stiffness gels were assessed by traction force microscopy essentially as describe ${ }^{5}$. Briefly, polyacrylamide substrates with shear moduli of $1 \mathrm{kPa}$ or $12 \mathrm{kPa}$ conjugated with fluorescent bead latex microspheres $(0.5 \mu \mathrm{m}, 505 / 515 \mathrm{~nm}$ ex/em) were purchased from Matrigen. After transfection, cells were plated on fluorescent bead-conjugated discrete stiffness gels and grown for 24 hours. Images of gel surface- 
conjugated fluorescent beads were acquired for each cell before and after cell removal using an Axiovert 200M motorized microscope stand (Zeiss) and a $\times 32$ magnification objective. Tractions exerted by cells were estimated by measuring bead displacement fields, computing corresponding traction fields using Fourier transform traction microscopy, and calculating rootmean-square traction using the PIV (Particle Image Velocimetry) and TFM (Traction force microscopy) package on Image ${ }^{46}$. To measure baseline noise, the same procedure was performed on a cell-free region.

\section{FRAP}

Celllight GFP-Tubulin (Thermo, C10613) were add to cells sixteen hours before experiment or Tubulin Tracker Green were add to cells thirty minutes before experiment to labelled polymerized tubulin in live cells. FRAP experiment were performed on Laser Scanning Confocal Microscope (LSM780 Carl Zeiss) equipped with a heated stage maintained at $37^{\circ} \mathrm{C}$ and the whole power of its $30 \mathrm{~mW} 488 \mathrm{~nm}$ Argon laser. Fluorescence intensity variations in microtubule were analyzed using the FRAP module of ZEN software (Carl Zeiss). Mobile fraction (in \%) and half-time of recovery (in seconds) values were extracted for each experiment.

\section{Circularity measurement}

The circularity index of cell shape was quantified as previously described ${ }^{47}$. For application of circularity measurements of cells, a freehand selection option in ImageJ software was used to delineate cell outline. Circularity index values were assigned to cell outlines by the ImageJ circularity plugin where circularity $=4 \mathrm{p}$ (area/perimeter2).

\section{Cell adhesion}

Cells were detached, washed three times with PBS and $3 \times 10^{4}$ cells were seeded per well of 24 well-plate previously coated with collagen. After 15 min of adhesion, cells were washed three times with PBS, fixed with PFA $4 \%$ and stained with DAPI. Cell adhesion were determined by counting all cells on the total area with Cytation5 Biotek System. Nuclei were counted and analyzed using Image $\mathrm{J}$ software.

\section{Cell proliferation}

Cells were detached, washed three times with PBS and $3 \times 10^{4}$ cells were seeded per well of 24 well-plate previously coated with collagen. After 24 hours of proliferation, cells were washed three times with PBS, fixed with PFA 4\% and stained with dapi. Cell proliferation was determined by imaging all the cells on the total area of the wells with a Image plate-reader (Cytation5, Biotek). Nuclei were counted and analyzed using ImageJ software. 


\section{Microtubules alignment analysis}

Cell alignment was calculated from microscopy images based on Local Gradients orientation method analysis using the directionality plug-in available through Image ${ }^{48}$. A histogram with the peak of the dominant orientation was produced for each representative image. A completely flat histogram represents an isotropic orientation ${ }^{49}$

\section{Live imaging and cell velocity/speed measurement}

Forty-two hours after siRNA transfection, cells were collected, reseeded on 24 wells plate, allowed to adhere, and migration was monitored at the earliest $4 \mathrm{~h}$ later. Cell migration was monitored by brightfield phase contrast microscopy using an Axiovert 200M videomicroscope (Carl Zeiss) with a $10 \times / 0.3 \mathrm{Ph} 1$ objective every $10 \mathrm{~min}$ for $2 \mathrm{~h}$ in a $37^{\circ} \mathrm{C}$ temperature-controlled environmental chamber. Persistence and velocity were analyzed using the Manual Tracking plugin of $\mathrm{Fiji}^{48}$.

\section{Glutamylated-tubulin intensity}

The mean intensity of Glu-Tubulin (Alexa488 fluorescence) in the cell area was measured with ImageJ software (NIH) as above on z-projections, after background correction.

\section{EB1 Comet Imaging Assays and Analysis}

The cells were imaged $24 \mathrm{~h}$ post transfection to measure the dynamicity of microtubules ends labeled with GFP-EB1. Images were acquired with a 488nm excitation on a spinning disk confocal microscope (Ultraview Vox, Perkin Elmer) equipped with a TiE Eclipse (Nikon Instruments) stand through a CFI PlanApochromat 100X/1.4 NA oil objective every 0.5 s during $1 \mathrm{~min}$ for each time-lapse. All the image analysis of the sequences was performed using MTrack plugin of Fijis

\section{Medium metabolite measurements}

For kinetics of metabolite secretion by HeLa cells, triplicate samples of subconfluent HeLa cultured under soft $(1 \mathrm{kPa})$ or stiff $(12 \mathrm{kPa}$ and $50 \mathrm{kPa})$ condition were changed to fresh DMEM with $10 \%$ FBS, which was allowed to condition for $48 \mathrm{~h}$. Metabolites were then extracted from conditioned medium by adding ice cold $100 \% \mathrm{MeOH}$ to a final concentration of $80 \% \mathrm{MeOH}$. Medium collected from cell-free plates after $48 \mathrm{~h}$ incubation was used as the baseline control to calculate the consumption or production of each metabolite, which was further normalized by the proliferation rate. The cell numbers were measured from duplicate treatment plates to determine the proliferation rate, and the metabolite flux was determined with the following formula: 
Uptake/secretion rate $=\Delta$ metabolite $/(\Delta$ time * average cell number $)$

Average cell number $=\Delta$ cell number $/\left(\right.$ growth rate ${ }^{\star} \Delta$ time $)$

Uptake/secretion rate $=(\Delta$ metabolite $/ \Delta$ time $) *($ growth rate $* \Delta$ time $/ \Delta$ cell number $)=(\Delta$ metabolite / $\Delta$ cell number) * growt rate

Growth rate $[1 / h]=$ LN (cell number T1) - LN (cell number T0) / time (T1)- time (T0)

\section{Targeted LC-MS}

Metabolite extraction was performed essentially as described with minor modifications ${ }^{5,51}$. Briefly, metabolites were extracted from cultured cells on dry ice using $80 \%$ aqueous methanol precooled at $-80^{\circ} \mathrm{C}$. Supernatants were extracted with 4 volumes of $100 \%$ methanol precooled at $-80^{\circ} \mathrm{C}$ for 4 hours at $-80^{\circ} \mathrm{C}$. An internal standard, $\left[{ }^{13} \mathrm{C}_{4}\right]-2$-oxoglutarate $\left(\left[{ }^{13} \mathrm{C}_{4}\right]-2 \mathrm{OG}\right)$ (Cambridge Isotope Laboratories), was added during metabolite extraction. Insoluble material from both cell and supernatant extractions was removed by centrifugation at 20,000 $\mathrm{g}$ for 15 minutes at $4^{\circ} \mathrm{C}$. The supernatant was evaporated to dryness by SpeedVac at $42{ }^{\circ} \mathrm{C}$, the pellet was resuspended in LC-MS water, and metabolites were analyzed by LC-MS.

LC-MS analysis was performed on a Vanquish ultra-high performance liquid chromatography system coupled to a $\mathrm{Q}$ Exactive mass spectrometer (Thermo) that was equipped with an Ion Max source and HESI II probe. External mass calibration was performed every seven days. Metabolites were separated using a ZIC-pHILIC stationary phase $(150 \mathrm{~mm} \times 2.1 \mathrm{~mm} \times 3.5$ $\mathrm{mm}$; Merck) with guard column. Mobile phase A was $20 \mathrm{mM}$ ammonium carbonate and $0.1 \%$ ammonium hydroxide. Mobile phase B was acetonitrile. The injection volume was $1 \mu \mathrm{L}$, the mobile phase flow rate was $100 \mu \mathrm{L} / \mathrm{min}$, the column compartment temperature was set at 25 ${ }^{\circ} \mathrm{C}$, and the autosampler compartment was set at $4{ }^{\circ} \mathrm{C}$. The mobile phase gradient (\%B) was $0 \mathrm{~min}, 80 \%$; $5 \mathrm{~min}$ 80\%; $30 \mathrm{~min}, 20 \%$; $31 \mathrm{~min}, 80 \%$; $42 \mathrm{~min}, 80 \%$. The column effluent was introduced to the mass spectrometer with the following ionization source settings: sheath gas 40 , auxillary gas 15 , sweep gas 1 , spray voltage $+/-3.0 \mathrm{kV}$, capillary temperature $275^{\circ} \mathrm{C}$, Slens RF level 40 , probe temperature $350^{\circ} \mathrm{C}$. The mass spectrometer was operated in polarity switching full scan mode from $70-1000 \mathrm{~m} / \mathrm{z}$. Resolution was set to 70,000 and the AGC target was $1 \times 10^{6}$ ions. Data were acquired and analysed using TraceFinder software (Thermo) with peak identifications based on an in-house library of authentic metabolite standards previously analysed utilizing this method. For all metabolomic experiments, the quantity of the metabolite fraction analysed was adjusted to the corresponding cell number calculated upon processing a parallel experiment.

\section{Measurements of metabolite levels by kits}


The levels of selected metabolites were measured by commercial kits to confirm the results of metabolic profiling. These include the glutamate colorimetric assay kit (BioVision) and the glutamine colorimetric assay kit (BioVision). The manufacturers' protocols were followed. Cell number was determined in concurrent experiment run in parallel, averaged per condition, and the metabolite consumption/production rates were calculated per cell.

\section{Glutaminase activity assay}

According to the manufacturer instructions (Glutaminase Microplate Assay Kit, Cohesion Biosciences), flash frozen tissue $(0.1 \mathrm{~g} / \mathrm{sample})$ or cells $\left(1 \times 10^{6}\right.$ cells) was homogenized in $1 \mathrm{~mL}$ of assay buffer on ice and centrifuged at $8000 \mathrm{~g} 4^{\circ} \mathrm{C}$ for $10 \mathrm{~min}$. Protein concentration was determined by Bradford assay. Samples, normalized to total protein $(100 \mu \mathrm{g})$ or cell numbers, were incubated with kit reagents for $1 \mathrm{hr}$ at $37^{\circ} \mathrm{C}$, and absorbances were measured at $420 \mathrm{~nm}$.

\section{Statistical analysis}

All analyses were performed using Prism 6.0 software (GraphPad Inc.). A two-tailed t-test was used if comparing only two conditions. For comparing more than two conditions, one-way ANOVA was used with: Bonferroni's multiple comparison test or Dunnett's multiple comparison test (if comparing all conditions to the control condition). Significance of mean comparison is marked on the graphs by asterisks. Error bars denote SEM.

\section{Data availability}

All the data are available upon reasonable request. 


\section{References}

1. DuFort, C. C., Paszek, M. J. \& Weaver, V. M. Balancing forces: architectural control of mechanotransduction. Nat. Rev. Mol. Cell Biol. 12, 308-319 (2011).

2. Iskratsch, T., Wolfenson, H. \& Sheetz, M. P. Appreciating force and shape-the rise of mechanotransduction in cell biology. Nat. Rev. Mol. Cell Biol. 15, 825-833 (2014).

3. Bertero, T. et al. Vascular stiffness mechanoactivates YAP/TAZ-dependent glutaminolysis to drive pulmonary hypertension. J. Clin. Invest. 126, 3313-3335 (2016).

4. Bays, J. L., Campbell, H. K., Heidema, C., Sebbagh, M. \& DeMali, K. A. Linking Ecadherin mechanotransduction to cell metabolism through force-mediated activation of AMPK. Nat. Cell Biol. 19, 724-731 (2017).

5. Bertero, T. et al. Tumor-Stroma Mechanics Coordinate Amino Acid Availability to Sustain Tumor Growth and Malignancy. Cell Metab. 29, 124-140.e10 (2019).

6. Romani, P. et al. Extracellular matrix mechanical cues regulate lipid metabolism through Lipin-1 and SREBP. Nat. Cell Biol. 21, 338-347 (2019).

7. Prahl, L. S. et al. Microtubule-Based Control of Motor-Clutch System Mechanics in Glioma Cell Migration. Cell Rep. 25, 2591-2604.e8 (2018).

8. Borisy, G. et al. Microtubules: 50 years on from the discovery of tubulin. Nat. Rev. Mol. Cell Biol. 17, 322-328 (2016).

9. Rape, A., Guo, W. \& Wang, Y. Microtubule depolymerization induces traction force increase through two distinct pathways. J. Cell Sci. 124, 4233-4240 (2011).

10. Xu, Z. et al. Microtubules acquire resistance from mechanical breakage through intralumenal acetylation. Science 356, 328-332 (2017).

11. Portran, D., Schaedel, L., Xu, Z., Théry, M. \& Nachury, M. V. Tubulin acetylation protects long-lived microtubules against mechanical ageing. Nat. Cell Biol. 19, 391-398 (2017).

12. Wloga, D., Joachimiak, E. \& Fabczak, H. Tubulin Post-Translational Modifications and Microtubule Dynamics. Int. J. Mol. Sci. 18, (2017).

13. Valenstein, M. L. \& Roll-Mecak, A. Graded Control of Microtubule Severing by Tubulin Glutamylation. Cell 164, 911-921 (2016). 
14. Brangwynne, C. P. et al. Microtubules can bear enhanced compressive loads in living cells because of lateral reinforcement. J. Cell Biol. 173, 733-741 (2006).

15. Brangwynne, C. P., MacKintosh, F. C. \& Weitz, D. A. Force fluctuations and polymerization dynamics of intracellular microtubules. Proc. Natl. Acad. Sci. 104, 16128$16133(2007)$

16. Hejnowicz, null, Rusin, null \& Rusin, null. Tensile Tissue Stress Affects the Orientation of Cortical Microtubules in the Epidermis of Sunflower Hypocotyl. J. Plant Growth Regul. 19, 31-44 (2000).

17. Cosentino Lagomarsino, M. et al. Microtubule organization in three-dimensional confined geometries: evaluating the role of elasticity through a combined in vitro and modeling approach. Biophys. J. 92, 1046-1057 (2007).

18. van Dijk, J. et al. A targeted multienzyme mechanism for selective microtubule polyglutamylation. Mol. Cell 26, 437-448 (2007).

19. Janke, C. \& Bulinski, J. C. Post-translational regulation of the microtubule cytoskeleton: mechanisms and functions. Nat. Rev. Mol. Cell Biol. 12, 773-786 (2011).

20. Rogowski, K. et al. A family of protein-deglutamylating enzymes associated with neurodegeneration. Cell 143, 564-578 (2010).

21. Colom, A. et al. A fluorescent membrane tension probe. Nat. Chem. 10, 1118-1125 (2018).

22. Dogterom, M. \& Koenderink, G. H. Actin-microtubule crosstalk in cell biology. Nat. Rev. Mol. Cell Biol. 20, 38-54 (2019).

23. Colin, A., Singaravelu, P., Théry, M., Blanchoin, L. \& Gueroui, Z. Actin-Network Architecture Regulates Microtubule Dynamics. Curr. Biol. CB 28, 2647-2656.e4 (2018).

24. Guilluy, C. et al. The Rho GEFs LARG and GEF-H1 regulate the mechanical response to force on integrins. Nat. Cell Biol. 13, 722-727 (2011).

25. Birkenfeld, J., Nalbant, P., Yoon, S.-H. \& Bokoch, G. M. Cellular functions of GEF-H1, a microtubule-regulated Rho-GEF: is altered GEF-H1 activity a crucial determinant of disease pathogenesis? Trends Cell Biol. 18, 210-219 (2008). 
26. Janke, C. The tubulin code: molecular components, readout mechanisms, and functions. J. Cell Biol. 206, 461-472 (2014).

27. Eddé, B. et al. Posttranslational glutamylation of alpha-tubulin. Science 247, 83-85 (1990).

28. Sahab, Z. J. et al. Analysis of tubulin alpha-1A/1B C-terminal tail post-translational polyglutamylation reveals novel modification sites. J. Proteome Res. 11, 1913-1923 (2012).

29. Redeker, V., Le Caer, J. P., Rossier, J. \& Promé, J. C. Structure of the polyglutamyl side chain posttranslationally added to alpha-tubulin. J. Biol. Chem. 266, 23461-23466 (1991).

30. Dupont, S. et al. Role of YAP/TAZ in mechanotransduction. Nature 474, 179-183 (2011).

31. Cho, S., Irianto, J. \& Discher, D. E. Mechanosensing by the nucleus: From pathways to scaling relationships. J. Cell Biol. 216, 305-315 (2017).

32. Torrino, S. et al. EHD2 is a mechanotransducer connecting caveolae dynamics with gene transcription. J. Cell Biol. 217, 4092-4105 (2018).

33. Swift, J. et al. Nuclear lamin-A scales with tissue stiffness and enhances matrix-directed differentiation. Science 341, 1240104 (2013).

34. Hamant, O., Inoue, D., Bouchez, D., Dumais, J. \& Mjolsness, E. Are microtubules tension sensors? Nat. Commun. 10, 2360 (2019).

35. Schaedel, L. et al. Microtubules self-repair in response to mechanical stress. Nat. Mater. 14, 1156-1163 (2015).

36. Lyons, J. S. et al. Microtubules tune mechanotransduction through NOX2 and TRPV4 to decrease sclerostin abundance in osteocytes. Sci. Signal. 10, (2017).

37. Liu, B. et al. IL-7Ra glutamylation and activation of transcription factor Sall3 promote group 3 ILC development. Nat. Commun. 8, 231 (2017).

38. Ye, B. et al. Klf4 glutamylation is required for cell reprogramming and early embryonic development in mice. Nat. Commun. 9, 1261 (2018).

39. Dijk, J. van et al. Polyglutamylation Is a Post-translational Modification with a Broad Range of Substrates. J. Biol. Chem. 283, 3915-3922 (2008). 
40. Birsoy, K. et al. An Essential Role of the Mitochondrial Electron Transport Chain in Cell Proliferation Is to Enable Aspartate Synthesis. Cell 162, 540-551 (2015).

41. Gierke, S. \& Wittmann, T. EB1-recruited microtubule +TIP complexes coordinate protrusion dynamics during 3D epithelial remodeling. Curr. Biol. 22, 753-762 (2012).

42. Matov, A. et al. Analysis of Microtubule Dynamic Instability Using a Plus End Growth Marker. Nat. Methods 7, 761-768 (2010).

43. Miller, L. M. et al. Methods in Tubulin Proteomics. Methods Cell Biol. 95, 105-126 (2010).

44. Eddé, B. et al. Polyglutamylated alpha-tubulin can enter the tyrosination/detyrosination cycle. Biochemistry 31, 403-410 (1992).

45. Paturle-Lafanechère, L. et al. Characterization of a major brain tubulin variant which cannot be tyrosinated. Biochemistry 30, 10523-10528 (1991).

46. Tseng, Q. et al. Spatial organization of the extracellular matrix regulates cell-cell junction positioning. Proc. Natl. Acad. Sci. U. S. A. 109, 1506-1511 (2012).

47. Torrino, S. et al. The E3 ubiquitin-ligase HACE1 catalyzes the ubiquitylation of active Rac1. Dev. Cell 21, 959-965 (2011).

48. Rueden, C. T. et al. ImageJ2: ImageJ for the next generation of scientific image data. BMC Bioinformatics 18, 529 (2017).

49. Liu, Z.-Q. Scale space approach to directional analysis of images. Appl. Opt. 30, 13691373 (1991).

50. Kapoor, V., Hirst, W. G., Hentschel, C., Preibisch, S. \& Reber, S. MTrack: Automated Detection, Tracking, and Analysis of Dynamic Microtubules. Sci. Rep. 9, 1-12 (2019). 51. Oldham, W. M., Clish, C. B., Yang, Y. \& Loscalzo, J. Hypoxia-Mediated Increases in I-2hydroxyglutarate Coordinate the Metabolic Response to Reductive Stress. Cell Metab. 22, 291-303 (2015). 
Acknowledgements: We thank the B. Mari team members for advice and discussions as well as F. Aguila for artwork. The author acknowledge the "Microscopie Imagerie Côte d'Azur" (MICA), GIS-IBISA multi-sites platform and particularly it's IPMC, C3M and IRCAN (Molecular and Cellular Imaging facility PICMI) partners. This platform is supported by the GIS IBiSA, Conseil Départemental 06, Région PACA ARC, Cancerôpole PACA,)". Proteomic analyses were performed at the mass spectrometry facility of Marseille Proteomics supported by IBISA, Plateforme Technologique Aix-Marseille, Canceropôle PACA, Région Sud Provence-AlpesCôte d'Azur, Fonds Européen de Développement Régional (FEDER) and Plan Cancer.

Funding: This work was supported by; the French National Research Agency ANR-18-CE140025 (to T.B.) as well as; NIH grant HL128802 (to W.M.O); NIH grants HL124021, HL 122596, HL 138437, UH2/UH3 TR002073, American Heart Association grant 18EIA33900027 (to S.Y.C.).

Author contributions: ST and TB conceived and designed the experiments. ST, SA, IB, WMO and TB performed the majority of the experiments. WMO, BM, and TB, provided the experimental infrastructure. CL generated tubulin mutants. FB performed and analysed FLIM experiments. SA performed STED experiments. SP performed and analysed AFM experiments. S. Audebert performed and analysed proteomic experiments. ST, WMO, BM, SYC, and TB wrote the manuscript. All authors participated in interpreting the results and revising the manuscript.

Competing interests: SYC has served as a consultant for Zogenix, Vivus, Aerpio, and United Therapeutics; SYC is a director, officer, and shareholder in Numa Therapeutics; SYC holds research grants from Actelion and Pfizer. SYC and TB have filed patent applications regarding the targeting of metabolism in pulmonary hypertension. The authors declare no competing interests 


\section{Figure Legends}

Figure 1: Mechanical cues force microtubules glutamylation to stabilize the microtubule lattice.

(a) Representative FRAP curves (left) and quantification of diffusion rate (t $1 / 2$ ) and mobile fraction (right) of GFP-Tubulin ( $n>45$ cells) (b) Representative kymographs (left) and growth rates quantification (right) of EB1-GFP in cells plated on the indicated substrate. $n>500$ comets. Scale bar=1 $\mu \mathrm{m}$. (c-d) Immunoblot and quantification of Glu-Tubulin in cells plated on the indicated substrate (c) or after hypo-osmotic shock (d). (e-f) Representative STED images of Tubulin and Glu-Tubulin localization (e) and representative alignment of microtubule (f) in cells plated on 1 or $50 \mathrm{kPa}$ hydrogel $(\mathrm{n}>10)$. Scale bar $=10 \mu \mathrm{m}$; for the inset, scale bar=1 $\mu \mathrm{m}$.; ${ }^{*} \mathrm{P}<0.05$; ${ }^{\star *} \mathrm{P}<0.01$; ${ }^{* \star *} \mathrm{P}<0.001$; ${ }^{* \star *} \mathrm{P}<0.0001$; (a-d) Bonferroni's multiple comparison test; data are mean \pm s.e. $m$ of at least $n=3$ independent experiments.

\section{Figure 2: Microtubule glutamylation rely on glutamine catabolism.}

(a-b) Heatmap (a) and pathway enrichment analysis (b) of significantly (FDR<1\%; P<0.05) modulated intracellular metabolites in cells followed indicated treatments. Red: metabolite from aspartate glutamate pathway (c) Immunoblot and quantification of Glu-Tubulin in SLC1A3 overexpressing cells plated on $1 \mathrm{kPa}$ hydrogel in presence of glutamate. (d) ${ }^{3} \mathrm{H}$-glutamine incorporation in purified microtubule from cells treated as indicated in presence of cycloheximide. (e-i) Cells plated on the indicated substrate and treated with CB839 or BPTES. (e) Immunoblot and quantification of Glu-Tubulin in cells in presence of glutamate. (f) Proteomic quantification of glutamylated C-terminal $\alpha$ - and $\beta$-tubulin tails in purified microtubule from cells treated as indicated. (g) Quantification of ${ }^{13} \mathrm{C}$-glutamine incorporation by stable carbon isotope proteomic in purified microtubule from cells treated as indicated in presence of cycloheximide. (h) Representative kymographs (left) and growth rates quantification (right) of EB1-GFP in presence of glutamate $n>500$ comets. Scale bar $=1 \mu \mathrm{m}$. (i) Representative FRAP curves (left) and quantification of diffusion rate $(\mathrm{t} t / 2)$ and mobile fraction (right) of GFP-Tubulin $(n>20)$ in presence of glutamate. ${ }^{*} P<0.05 ;{ }^{*} P<0.01 ; \quad{ }^{* \star *} P<0.001$; ${ }^{* \star \star \star} \mathrm{P}<0.0001$; (c,e-g,i) Bonferroni's multiple comparison test; (d) two tailed t-test; data are mean \pm s.e. $m$ of at least $n=3$ independent experiments.

\section{Figure 3: TTLL4 force microtubule glutamylation to adjust cell mechanics and sustain} cell mechanic-dependent activities.

(a-f,h) HeLa cells plated on $50 \mathrm{kPa}$ hydrogel were transfected with the indicated SiRNA. (a) Immunoblot and quantification of Glu-Tubulin in cells. (b) Representative confocal images (left) and quantification (right) of Glu-Tubulin and Tubulin. Scale bar=10 $\mu \mathrm{m}$. (c) Representative kymographs (left) and growth rates quantification (right) of EB1-GFP. n>500 comets. Scale 
bar=1 $\mu \mathrm{m}$. (d) Representative FRAP curves (left) and quantification of diffusion rate ( $\mathrm{t} 1 / 2)$ and mobile fraction (right) of GFP-Tubulin. (e) Apparent Young's moduli obtained by AFM analysis. Bars represent the median. (f) Representative heat map (left) and quantification (right) showing contractile forces generate by cells. (g) Representative confocal images (left) and quantification (right) of circularity index. Scale bar $=10 \mu \mathrm{m}$. In all the panels $\mathrm{n}>20$ cells from 3 independent experiments were analyzed. ${ }^{*} \mathrm{P}<0.05$; ${ }^{*} \mathrm{P}<0.01$; ${ }^{* *} \mathrm{P}<0.001$; ${ }^{\star * \star *} \mathrm{P}<0.0001$; (b$\mathbf{d}, \mathbf{g})$ Bonferroni's multiple comparison test; (f) two tailed t-test; data are mean \pm s.e.m.

Figure 4: Microtubule glutamylation is sufficient to adjust cell mechanics and sustain cell mechanic-dependent activities.

(a) Schematic representation of TUBA1A structure in wild type and mutant. (b-g) HeLa cells were transfected with TUBA1A constructs. (b) Immunoblot and quantification of Glu-Tubulin in cells. (c) Representative confocal images (left) and quantification (right) of Glu-Tubulin and Tubulin. Scale bar=10 $\mu \mathrm{m}$. *: Transfected cell (d) Representative kymographs (left) and growth rates quantification (right) of EB1-GFP. $n>500$ comets. Scale bar=1 $\mu \mathrm{m}$. (e) Apparent Young's moduli obtained by AFM analysis. Bars represent the median. (f) Representative heat map (left) and quantification (right) showing contractile forces generate by cells. (g) Representative confocal images (left) and quantification (right) of circularity index. Scale bar=10 $\mu \mathrm{m}$. In all the panels $n>50$ cells from 3 independent experiments were analyzed. ${ }^{\star \star} P<0.01 ;{ }^{\star \star *} P<0.001$; $\left.{ }^{\star \star \star \star \star} \mathrm{P}<0.0001 ; \mathbf{( b}, \mathbf{f}-\mathbf{g}\right)$ Bonferroni's multiple comparison test; (e) two tailed t-test; data are mean \pm s.e.m. 
a Stiffness Osmotic shock $(\mathrm{kPa})-(\mathrm{min})$

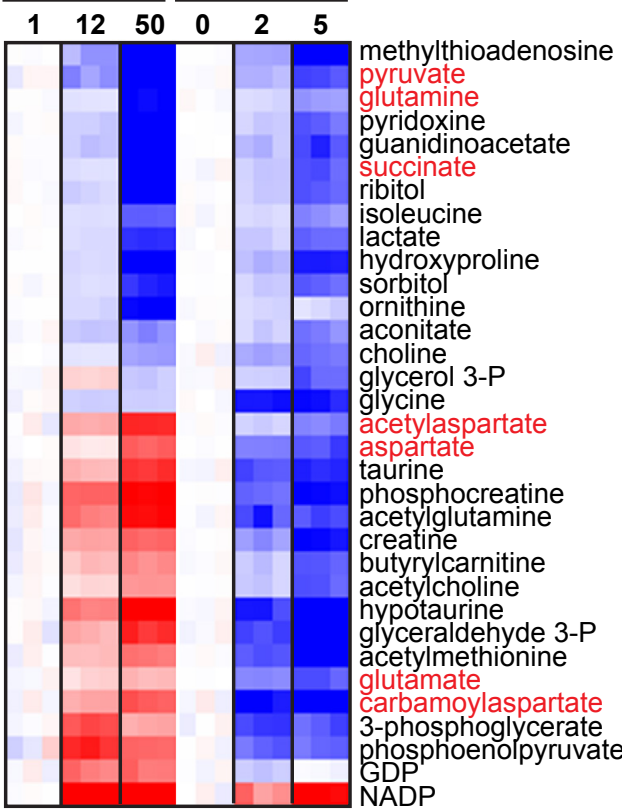

Log2 fold change

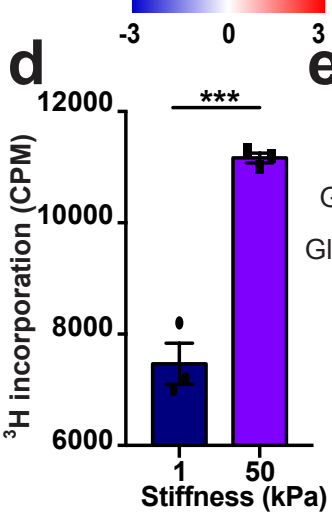

g

.
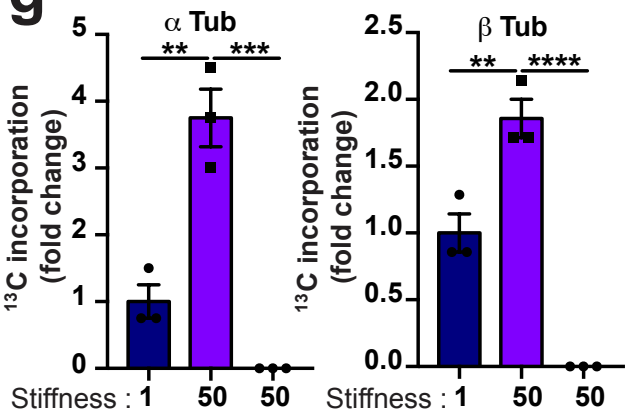

Stiffness : $\mathbf{1} \quad \mathbf{5 0} \quad \mathbf{5 0}$ Stiffness : $\mathbf{1} \quad \mathbf{5 0} \quad \mathbf{5 0}$

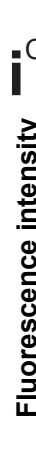

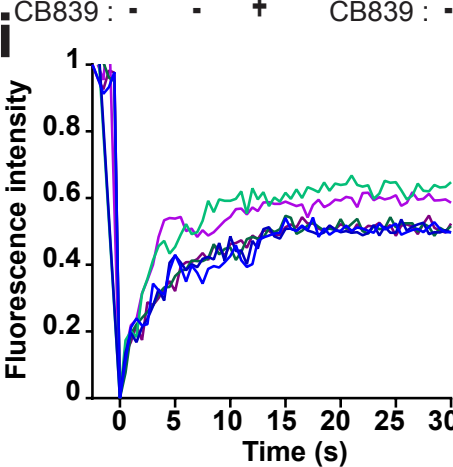

-Log10 FDR

$\begin{array}{llllll}0 & 1 & 2 & 3 & 4 & 5\end{array}$

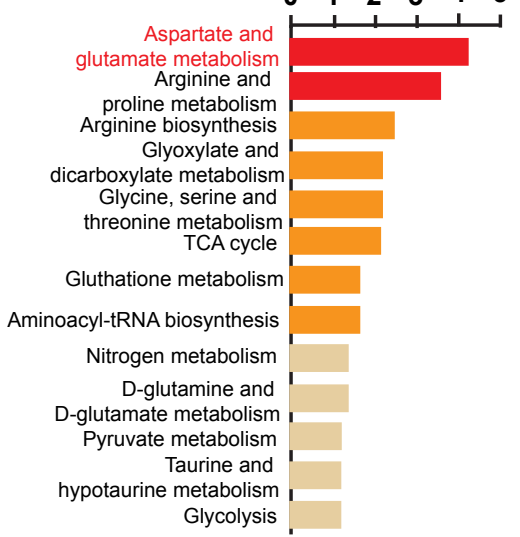

Glycolysis

Clycolysis
$\underset{(\mathrm{mM})}{\operatorname{Glutamate}:}$

Glu-Tubulin

Hsp 90

Tubulin

Hsp 90

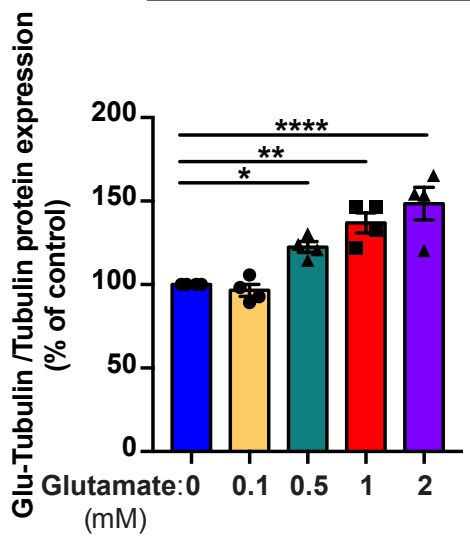

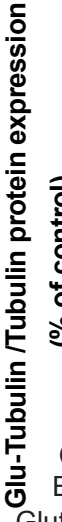

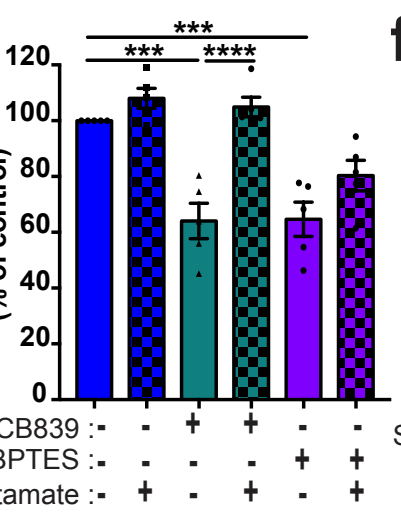

f
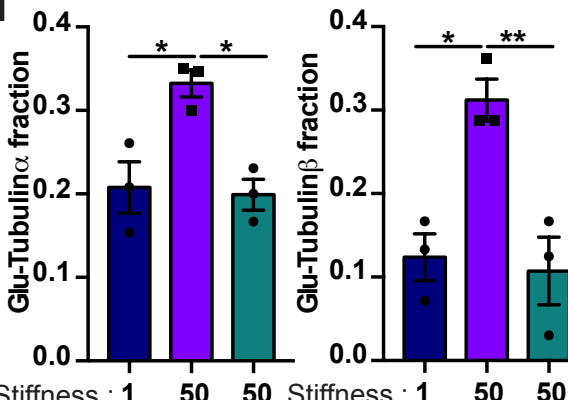

$h$ EB1-GFP

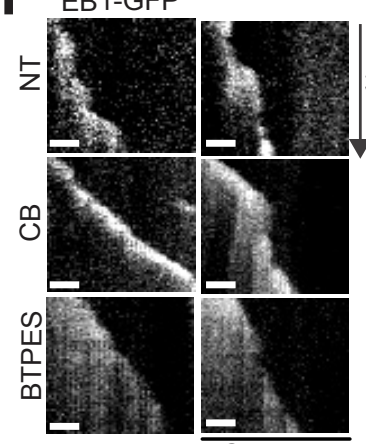

+ Glutamate

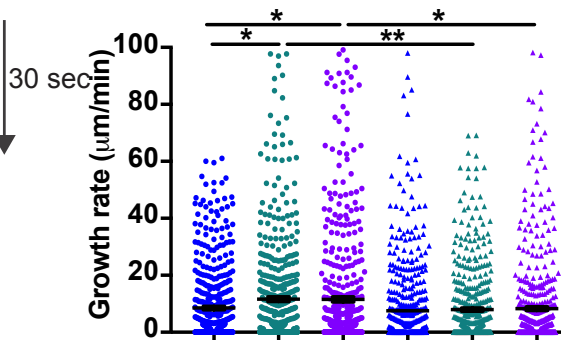

\section{CB839:}

$(\mathrm{kPa})$

CB839 : .

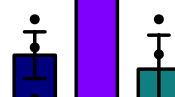

\section{BPTES :}

Glutamate:

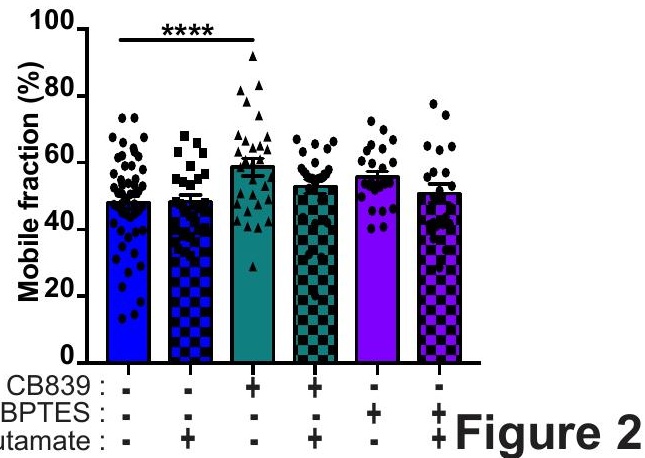


a Glu-Tubulin E-ZEEE-日の

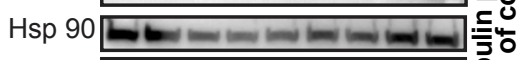
Tubulin Hsp 90
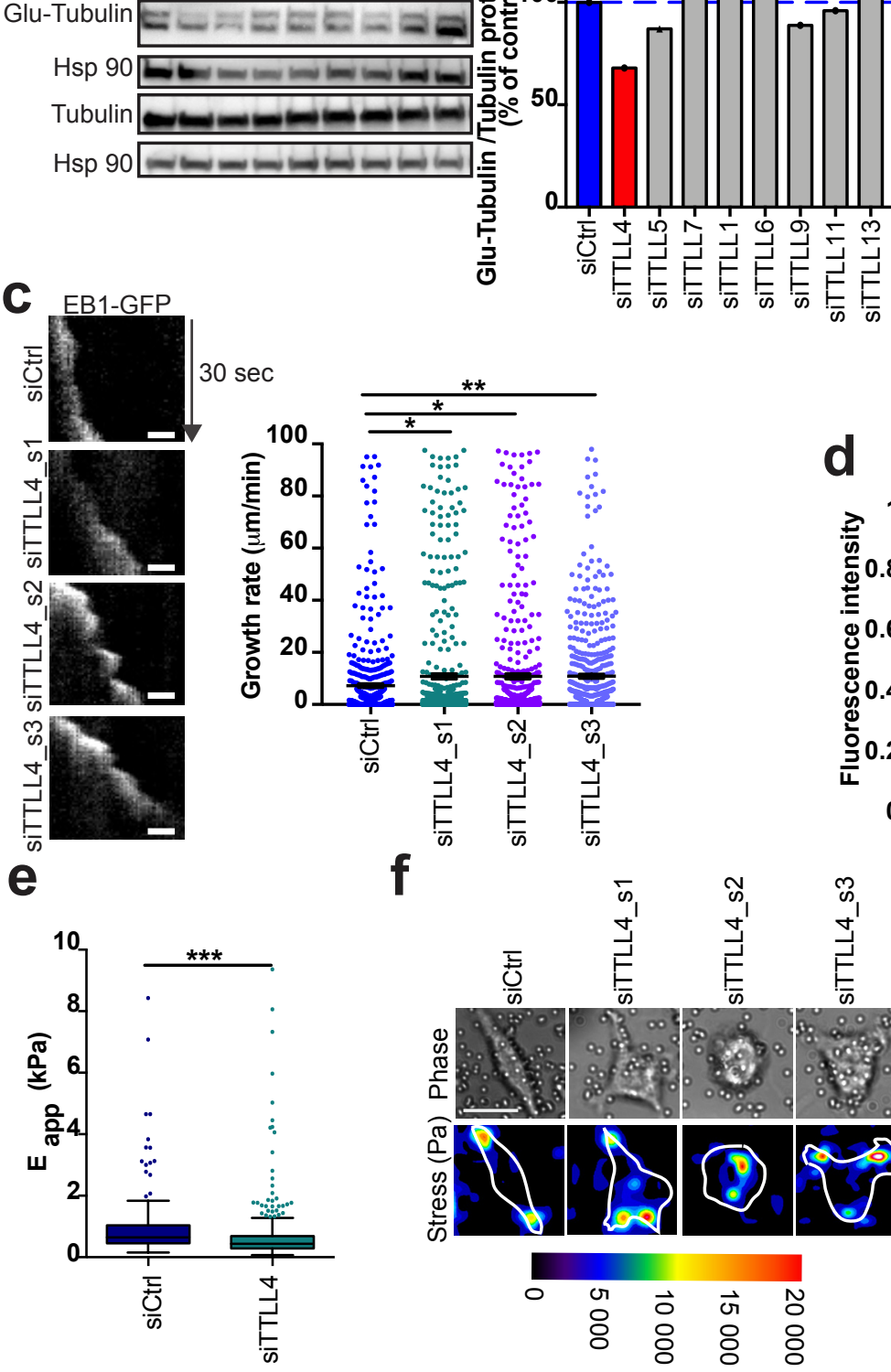

Tubulin Glu-Tubulin MERGE

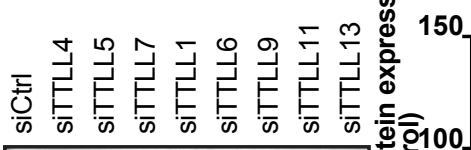

g

$50 \mathrm{kPa}$

d

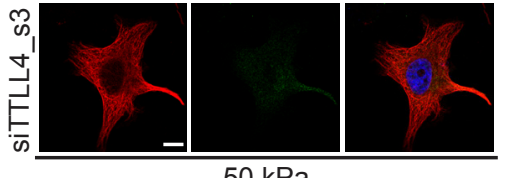

$50 \mathrm{kPa}$

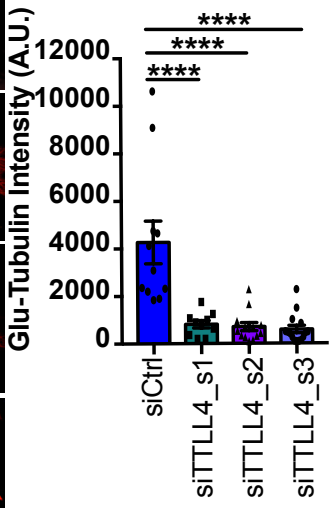

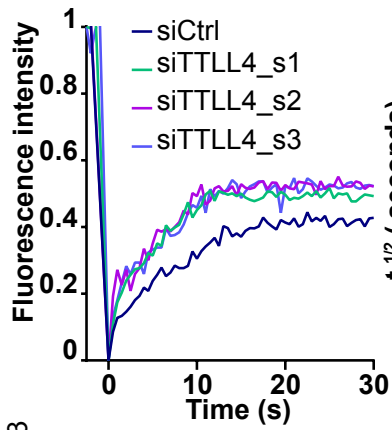

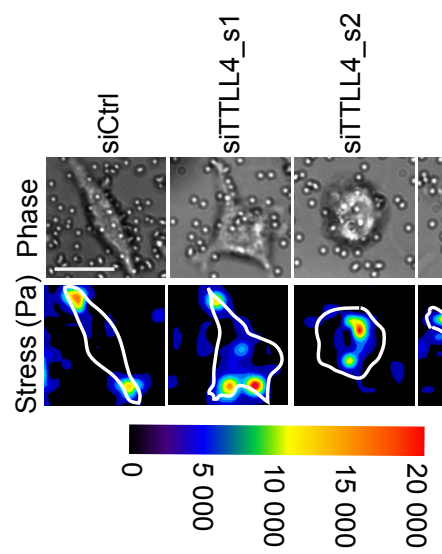

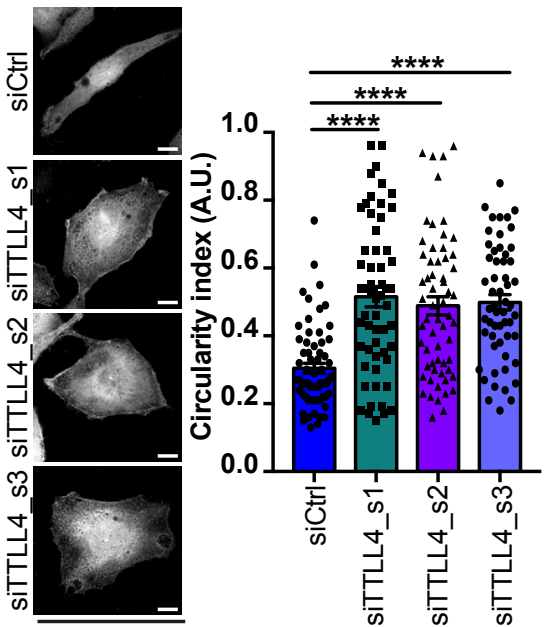

Figure 3 


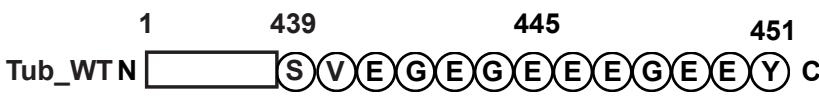

Tub $\triangle$ Cterm N $\mathrm{N}$ (S) C

Tub_E445D N $\square($ (D)(E)(E)(D)(E)(G)(E) C

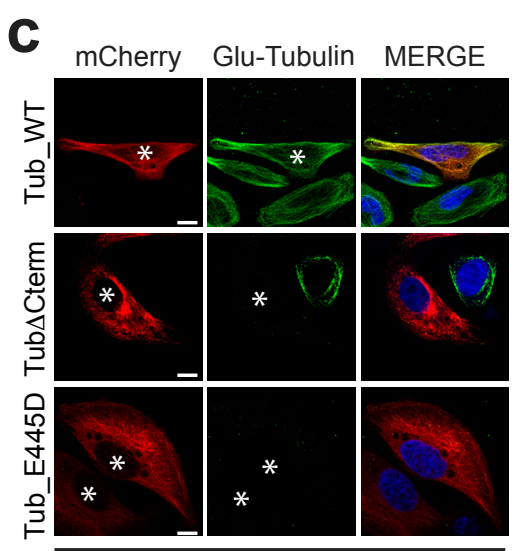

$50 \mathrm{kPa}$

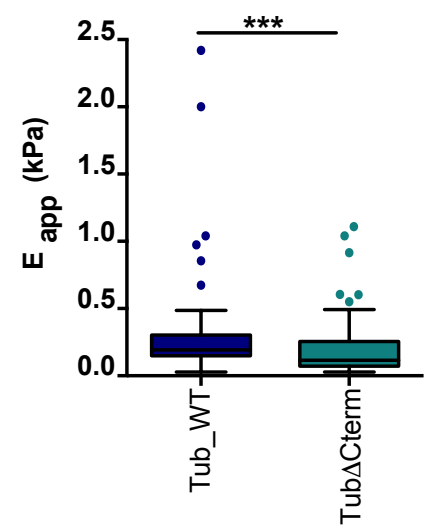

g

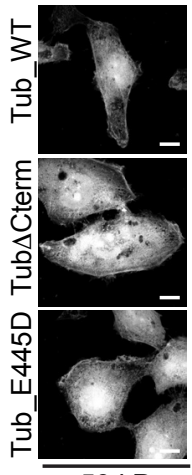

$50 \mathrm{kPa}$

$50 \mathrm{kPa}$

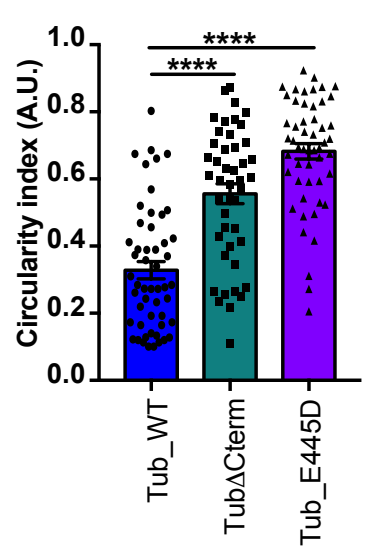

d

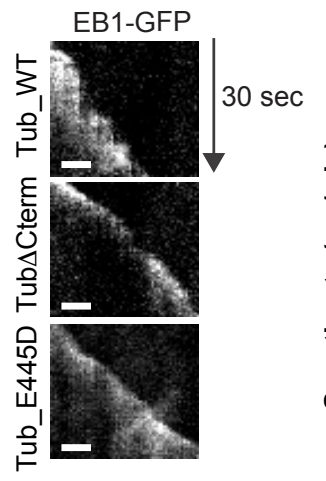

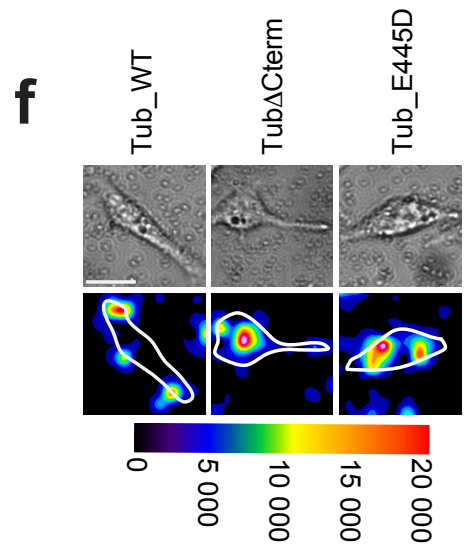
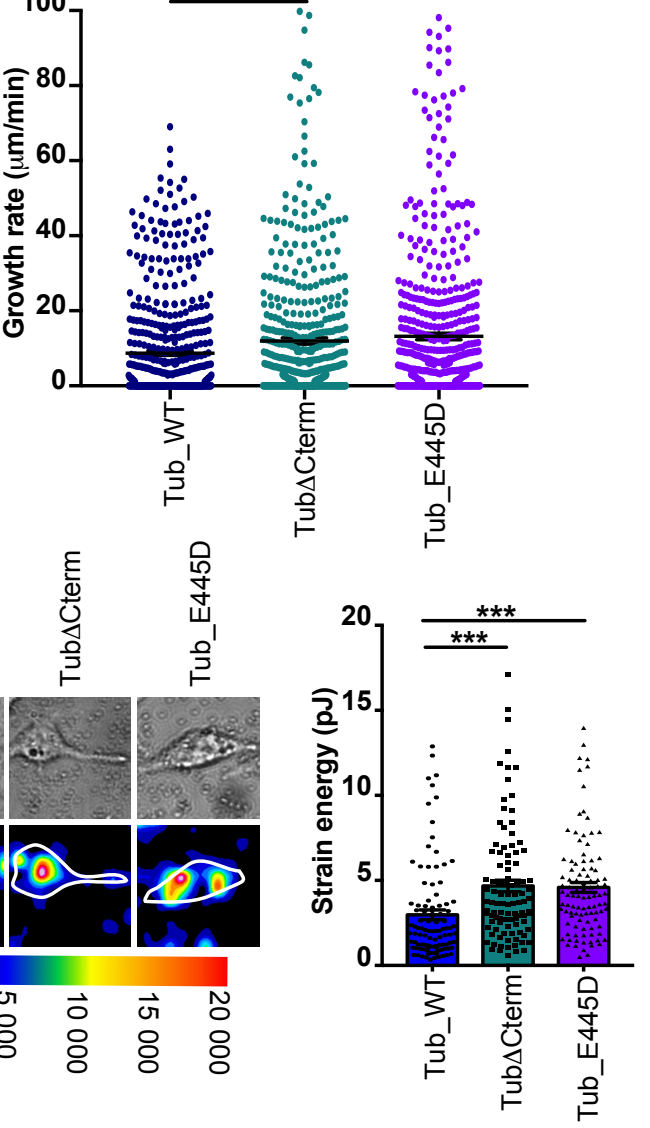

Figure 4 


\section{Extended data for}

Biophysical forces rewire cell metabolism to guide microtubule-dependent cell mechanics

Stephanie Torrino ${ }^{\$}$, Stephan Audebert, Ilyes Belhadj, Caroline Lacoux, Sabrina Pisano,

Sophie Abélanet, Frederic Brau, Stephan Y. Chan, Bernard Mari, William M Oldham, and Thomas Bertero $\$$

\$Corresponding Authors. Email: : thomas.bertero@univ-cotedazur.fr;

stephanie.torrino@univ-cotedazur.fr

This PDF file includes:

Extended Figure 1 to 8 


\section{Extended figure 1: Mechanical cues increase microtubules glutamylation and alter microtubules dynamics to force cell mechanics.}

(a) Representative FRAP curves (left) and quantification of diffusion rate (t $1 / 2$ ) and mobile

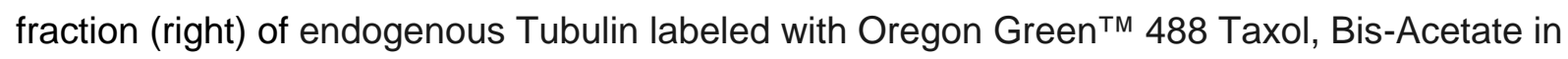
HeLa cells plated on different stiffness hydrogel $(1,12,50 \mathrm{kPa})$ or plastic ( $\mathrm{n}>45 \mathrm{kells})$. (b) Representative heat map (left) and quantification (right; $n>15$ cells from $n=3$ independent experiments) showing contractile forces generate by cells plated on $12 \mathrm{kPa}$ hydrogel and treated with Nocodazole or Taxol. (c) Immunoblot and quantification ( $n=3$ independent experiments) of Glu-Tubulin in HeLa cells plated on $1 \mathrm{kPa}$ hydrogel and after shear stress for the indicated times. Hsp90 was used as a loading control. (d,e) Immunoblot of Glu-Tubulin in MDA-MB-468 cells (d) and primary pulmonary arterial smooth muscle cells (PASMCs; e) plated on the indicated substrate. (f,h) Representative confocal images of Tubulin and GluTubulin localization in HeLa cells plated on different stiffness hydrogel $(1,12,50 \mathrm{kPa})$ or plated on $1 \mathrm{kPa}$ hydrogel and after osmotic stress for the indicated times. Nuclei were stained with DAPI (Blue) on the MERGE image. Quantification (right) of Glu-Tubulin intensity in the different condition. At least 50 cells per condition. Scale bar=10 $\mu \mathrm{m}$. (g) Representative alignment of microtubule in HeLa cells plated on different stiffness hydrogel (1, 12, $50 \mathrm{kPa})$. At least 10 cells per condition. $\mathrm{n}=3$ independent experiments; ${ }^{* \star} \mathrm{P}<0.01$; ${ }^{* \star} \mathrm{P}<0.001 ;{ }^{* \star \star *} \mathrm{P}<0.0001$; (a-c) Bonferroni's multiple comparison test; data are mean \pm s.e.m.

\section{Extended figure 2: Mechanoactivation of GLS-dependent glutamine catabolism sustain the intracellular glutamate pool.}

(a-d) Heatmap $(\mathbf{a}, \mathbf{b})$ and pathway enrichment analysis $(\mathbf{c}, \mathbf{d})$ of significantly (FDR $<1 \% ; \mathrm{P}<0.05)$ modulated intracellular metabolites in cells plated on the indicated substrate $(\mathbf{a}, \mathbf{c})$ or after hypoosmotic shock (b,d). Red: metabolite from aspartate glutamate pathway. (e,f) Glutamate/Glutamine ratio in cells plated on the indicated substrate (e) or after hypo-osmotic shock (f). Data are extract from (a-b) analysis. (g) Glutamine flux of HeLa cells plated on hydrogel of the indicated stiffness $(n=3)$. $(\mathbf{h}-\mathbf{i})$ HeLa cells plated on different stiffness hydrogel $(1,12,50 \mathrm{kPa})$ or plastic. (h) Immunoblot and quantification ( $\mathrm{n}=3)$ of GLS. (i) Measurement of GLS activity in cells treated with CB839 for 24h. (j) Intracellular glutamate level of HeLa cells overexpressing SLC1A3 cultivated on $1 \mathrm{kPa}$ hydrogel and in presence of various glutamate concentration $(n=3)$. 


\section{Extended figure 3: Either genetic or pharmacologic inhibition of GLS rewired glutamate} metabolism

(a-d) Heatmap (a,c) and pathway enrichment analysis (d) of significantly (FDR<1\%; P<0.05) modulated intracellular metabolites in cells following indicated treatments. Red: metabolite from aspartate glutamate pathway.

\section{Extended figure 4: Mechanoactivation of GLS-dependent glutamine catabolism sustain microtubules glutamylation under mechanical stresses.}

(a-b, d-e) HeLa cells plated on the indicated substrate and treated with CB839 or BPTES. (a) Immunoblot and quantification ( $\mathrm{n}=3$ independent experiments) of Glu-Tubulin in cells. (b) Immunoblot and quantification ( $n=3$ ) of Glu-Tubulin in HeLa cells after osmotic stress for the indicated times. Hsp90 was used as a loading control. (c) Immunoblot and quantification $(n=3)$ of Glu-Tubulin in HeLa cells transfected with the siRNA GLS in presence of glutamate for $24 \mathrm{~h}$. (d) Representative confocal images (left) and quantification (right; $n>50$ cells from $n=3$ independent experiments) of Glu-Tubulin and Tubulin in presence of glutamate for $24 \mathrm{~h}$. Nuclei were stained with DAPI (Blue) on the MERGE image.Scale bar=10 $\mu \mathrm{m}$. At least 50 cells per condition from 3 independent experiments. Scale bar=10 $\mu \mathrm{m}$. (e) Representative alignment of microtubule in cells in presence of glutamate for $24 \mathrm{~h}$. At least 10 cells per condition from $n=3$ independent experiments; ${ }^{\star} \mathrm{P}<0.05 ; \quad{ }^{*} \mathrm{P}<0.01 ;{ }^{* \star *} \mathrm{P}<0.001 ;{ }^{* \star \star *} \mathrm{P}<0.0001 ; \quad(\mathbf{a}, \mathbf{b})$ two-way ANOVA and Dunnett's multiple comparisons test; (c,d) Bonferroni's multiple comparison test;; data are mean \pm s.e.m.

\section{Extended figure 5: Balanced microtubules glutamylation by TTL4 and CCP5 organize the microtubule lattice.}

(a-i) HeLa cells were transfected with the indicated siRNA (control, siCtrl; TTLL and CCP, siRNA smarpool or siRNA single, _s1, s2, s3) for 48h. (a,c-d) As demonstrated by RT-qPCR, effective siRNA knockdown was achieved in Hela cells. For each gene transcript, mean expression in control groups (siCtrl) were assigned a fold change of 1 , to which relevant samples (transfected with a siRNA specific to that gene) were compared. (b,e-f) Immunoblot (b,e-f) and quantification (b) of Glu-Tubulin in cells. (g, i) Representative alignment of microtubule in cells in plated on $50 \mathrm{kPa}(\mathbf{g})$ or $1 \mathrm{kPa}$ (i) hydrogels. (h) Representative confocal images (left) and quantification (right; $\mathrm{n}>50$ cells from 3 independent experiments) of GluTubulin and Tubulin in cells plated on $1 \mathrm{kPa}$ hydrogel. Scale bar=10 $\mu \mathrm{m}$. At least 10 cells per condition from $\mathrm{n}=3$ independent experiments; ${ }^{*} \mathrm{P}<0.05$; ${ }^{* *} \mathrm{P}<0.01$; ${ }^{* \star *} \mathrm{P}<0.001$; ${ }^{* \star \star * P} \mathrm{P}<0.0001$; (a) two-way ANOVA and Dunnett's multiple comparisons test; (c-d, h) Bonferroni's multiple comparison test; data are mean \pm s.e.m. 
Extended figure 6: Microtubules glutamylation is orchestrated by TTLL4 and CCP5 to adjust cell mechanics and sustain cell mechanic-dependent activities.

(a-j) HeLa cells were transfected with the indicated siRNA (control, siCtrl; TTLL and CCP, siRNA single, _s1, s2, s3) for 48h. (a) Representative kymographs (left) and growth rates quantification (right) of EB1-GFP in cells plated on $1 \mathrm{kPa}$ hydrogel. $n>500$ comets. Scale bar $=1$ $\mu \mathrm{m}$. (b) Representative FRAP curves (left) and quantification of diffusion rate ( $\mathrm{t} 1 / 2)$ and mobile fraction (right) of GFP-Tubulin in cells plated on $1 \mathrm{kPa}$ hydrogel ( $\mathrm{n}>45$ cells). (c) Representative heat map (left) and quantification (right) showing contractile forces generate by cells plated on $12 \mathrm{kPa}$ hydrogel. (d) Representative confocal images (left) and quantification (right) of circularity index of cells plated on $1 \mathrm{kPa}$ hydrogel. Scale bar $=10 \mu \mathrm{m}$. (e-f) Proliferation rate of cells plated on $50 \mathrm{kPa}(\mathbf{e})$ or $1 \mathrm{kPa}(\mathbf{f})$ hydrogel. (g-h) Measurement of cell adhesion on cells plated on $50 \mathrm{kPa}(\mathbf{g})$ or $1 \mathrm{kPa}(\mathbf{h})$ hydrogel. (i-j) Cell velocity (left) and speed (right) of cells plated on $50 \mathrm{kPa}(\mathbf{i})$ or $1 \mathrm{kPa}(\mathbf{j})$ hydrogel. In all the panels $\mathrm{n}>50$ cells from 3 independent experiments were analyzed. ${ }^{*} \mathrm{P}<0.05$; ${ }^{\star \star} \mathrm{P}<0.01$; ${ }^{\star \star *} \mathrm{P}<0.001$; ${ }^{\star \star \star *} \mathrm{P}<0.0001$; (a-j) Bonferroni's multiple comparison test; data are mean \pm s.e.m.

\section{Extended figure 7: TTLL5 orTTLL9 cell depletion decreased MT glutamylation,} reorganize the microtubule lattice and affect cell mechanic-dependent cell functions

(a-I) HeLa cells were transfected with the indicated siRNA (control, siCtrl; TTLL and CCP, siRNA single, _s1, s2, s3) for $48 \mathrm{~h}$ and plated on $50 \mathrm{kPa}$ hydrogel. $(\mathbf{a}, \mathbf{b})$ Immunoblot of GluTubulin in cells. (c,e) Representative confocal images (left) and quantification (right; $n>50$ cells from 3 independent experiments) of Glu-Tubulin and Tubulin in cells. Scale bar=10 $\mu \mathrm{m}$. At least 10 cells per condition from $n=3$ independent experiments. $(\mathbf{d}, \mathbf{f})$ Representative alignment of microtubule in cells. (g,h) Quantification of circularity index of cells. (i-j) Proliferation rate of cells. (k-l) Cell velocity (left) and speed (right) of cells. In all the panels $n>50$ cells from 3 independent experiments were analyzed. ${ }^{*} \mathrm{P}<0.05 ;{ }^{*} \mathrm{P}<0.01 ; \quad{ }^{* \star *} \mathrm{P}<0.001 ; \quad{ }^{*} * \star \mathrm{P}<0.0001$; (c,e,g-I) Bonferroni's multiple comparison test; data are mean \pm s.e.m.

Extended figure 8: C-terminal tubulin tail mutants increase microtubule dynamics and modulate cell mechanic-dependent activities.

(a-d) HeLa cells were transfected with TUBA1A constructs and plated on 50kPa hydrogel. (a) Representative alignment of microtubule in cells. (b) Representative FRAP curves (left) and quantification of diffusion rate (t $1 / 2)$ and mobile fraction (right) of GFP-Tubulin in cells. (c) Proliferation rate of cells. (d) Cell velocity (left) and speed (right) of cells. In all the panels $n>50$ cells from 3 independent experiments were analyzed. ${ }^{*} P<0.05 ;{ }^{*} P<0.01 ; \quad{ }^{* *} P<0.001$; $\star \star \star \star P<0.0001$; (c-d) Bonferroni's multiple comparison test; data are mean \pm s.e.m. 
a bioRxiv preprint doi: https://doi. Stiffness (kPa) (which was not certified by peerQsmequjshocku(min)funder. All rights reserved. No reuse allowed without permission.

\begin{tabular}{|c|c|c|c|}
\hline 1 & 12 & 50 & \\
\hline & & & 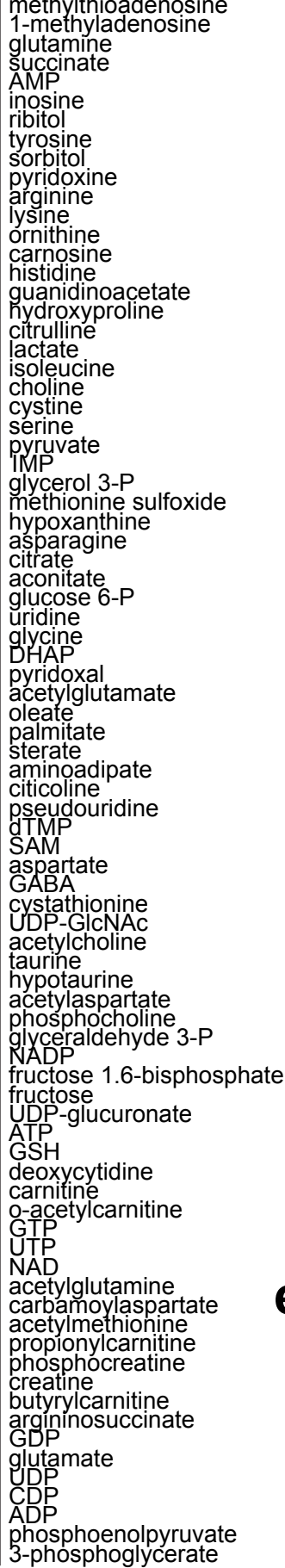 \\
\hline \multicolumn{4}{|c|}{ g2 fold change } \\
\hline & 0 & 3 & \\
\hline
\end{tabular}

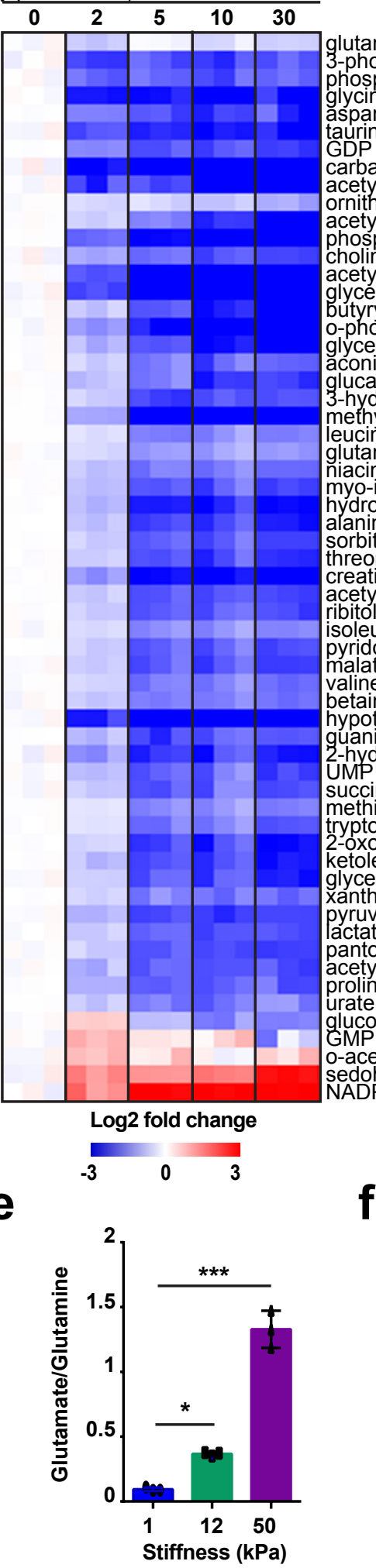

glutamate

-phosphoglycerate

年

spartate

taurine

Garbamoylaspartate

Arginine and proline metabolism

Aminoacyl-tRNA biosynthesis

Pyrimidine metabolism

TCA cycle

Purine metabolism

Glyoxylate and dicarboxylate metabolism

actyimethionine

alyceraldehyde 3-P

butyrylcarnitine

Cysteine and methionine metabolism

(tycerophosphocholine serine and threonine metabolism

aconitate

glucaric acid

Glycolysis'

hydroxybutyrate

作

glutamine

niacinamide

hydroxyproline

alanine

sorbitol

threonine

creatine

acetylcholine

soleucine

pyridoxine

malate

valine

hypotaurine

guanidinoacetate

-hydroxyglutarate

succinate

methionine

tryptophan

exoglutarate

glycerol 3-P

xanthine

pyruvate

pantothenate

acetylalanine

proline

urate

lucose

-acetylserine

sedoheptulose 7-P

d

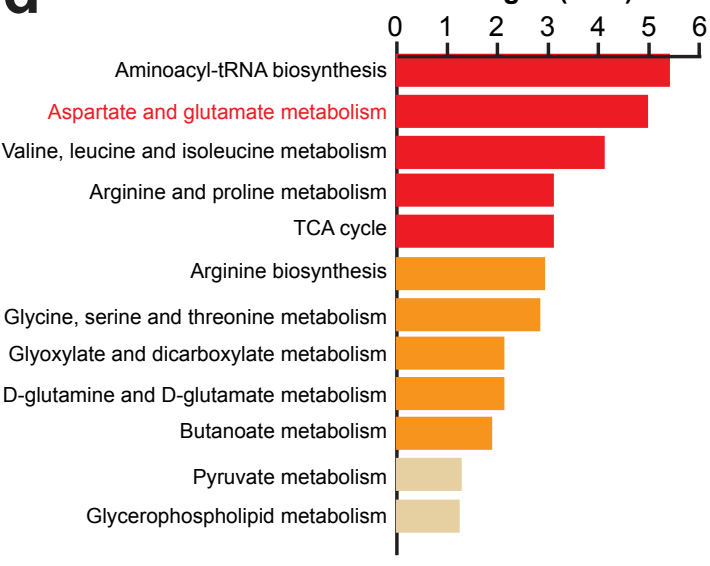

(

-Log10 (FDR)

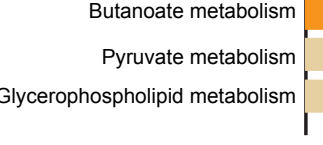

Stiffness: $122412 \quad 50$ Plastic

(kPa)

GLS

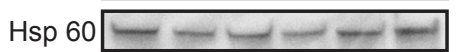

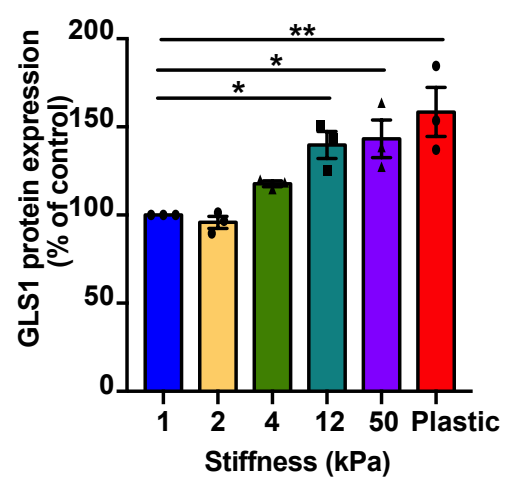

i

f
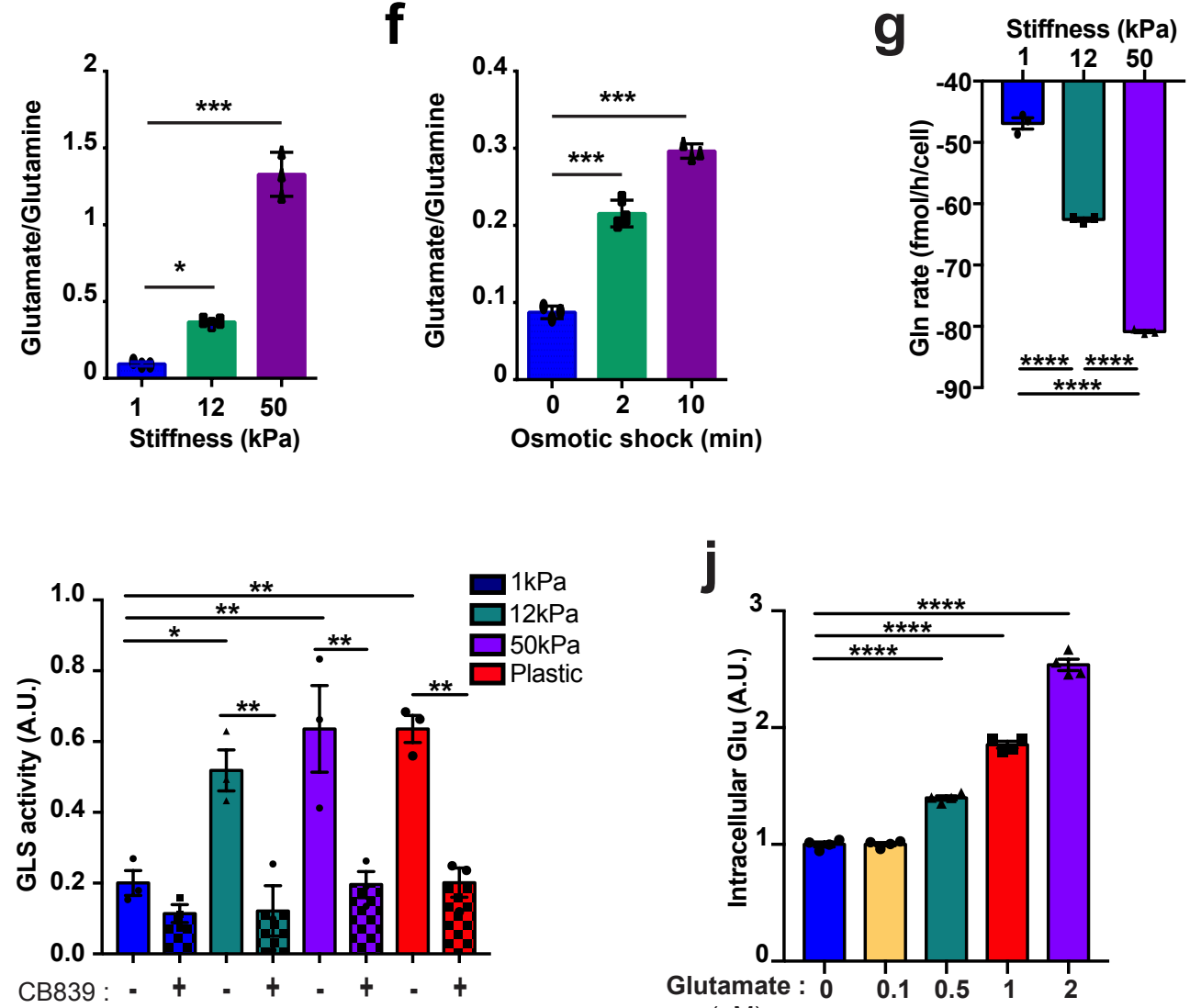

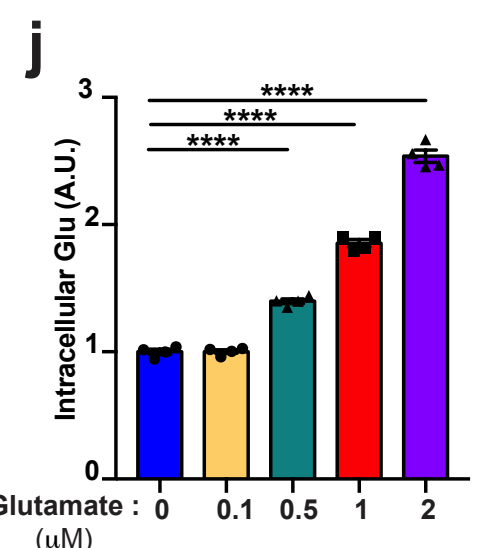

Extended Figure 2 


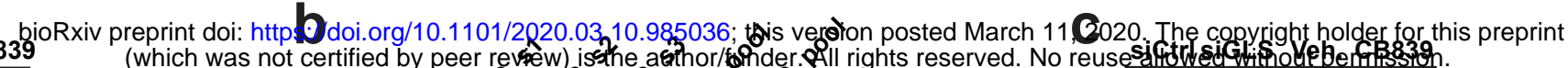

Vh. CB839 carbamoylaspartate

glucaric acid

deoxycytidine

proline

dTMP

CTP

glutamate

malate

citrate

onylcarnitine

1.6-bisphosphate

o-acetylcarnitine

UDP-glucuronate

arginosuccinate

creatine

pseudouridine

2-hydroxyglutarate

acetylcholine

carnitine

hypotaurine

acetylaspartate

GTP

fumarate

NADP

aspartate

taurine

butyrylcarnitine

aconitate

NAD

2-oxoglutarate

methionine sulfoxide

xanthosine

3-phosphoglycerate

succinate

glutamine

pyridoxal

gholine

histidine

threonine

lactate

pyruvate

-phosphoethanolamine

isoleucine

citicoline

asparagine

citrulline

ornithine

trimethyllysine

guanidinoacetate

2-hydroxybutyrate

pyridoxine

hydroxyproline

carnosine

valine

tryptophan

uridine

3-hydroxybutyrate

arginine

lysine

methionine

niacinamide

tyrosine

xans

GSSG

palmitate

stearate

ketoleucine

kynurenine

phenylalanine

eucine

UMP

glycerol

creatinine

glucose 1-P

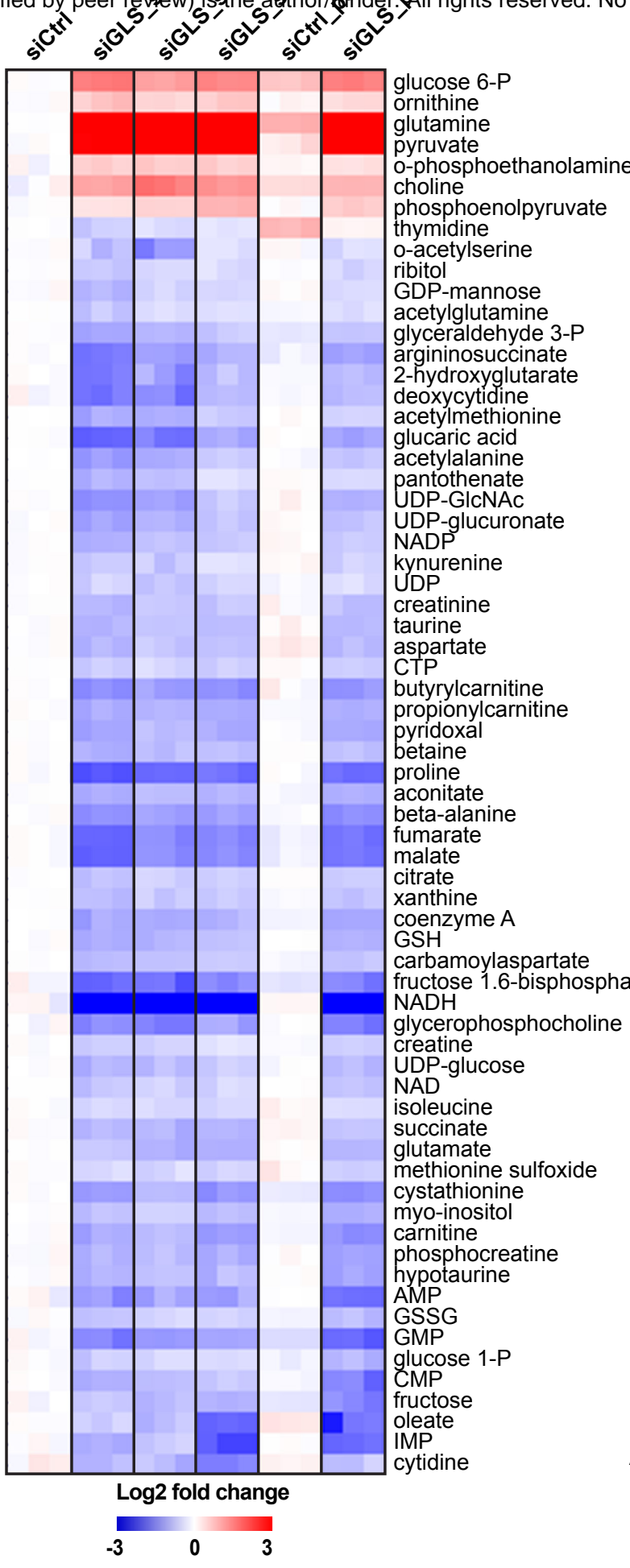

D deoxycytidine UDP-glucoronate

propionylcarnitine

carnitine

hypotaurine

glutamate

aspartate

\begin{tabular}{l|l|l} 
o-phosphoethanolamine & & aspartat \\
choline & & NADP \\
phosphoenolpyruvate & & GSH
\end{tabular}

- $\quad$ GSH

carbamo

aconitate

butyrylcarnitine

proline

IMP

cystathionine

2-hydroxyglutarate

creatine

citrate

fumarate

malate

arginosuccinate

NAD

fructose 1,6-bisphosphate

glucaric acid

glucose 1-P

creatinine

methionine sulfoxide

kynurenine

isoleucine

pyridoxal

succinate

xanthine

ribitol

GSSG

o-phosphoethanolamine

ornithine

choline

pyruvate

glutamine

Log2 fold change
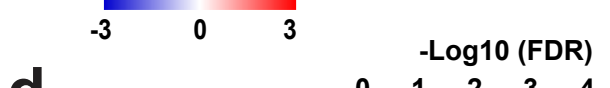

d

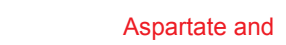

glutamate metabolism

Arginine biosynthesis

Glyoxylate and

dicarboxylate metabolism

Glutathione metabolism

Arginine and proline metabolism Nicotinate and

nicotinamide metabolism Aminoacyl-tRNA biosynthesis

Glycine, serine and

threonine metabolism

Nitrogen metabolism

D-glutamine and

D-glutamate metabolism

Ascorbate and aldarate metabolism

Pyruvate metabolism 
a bioRxiv preprint doi: https://doi.org/10.1101/2820.03.10.985036; this version posted March $* * 2020$. The pppeght holder for this preprint

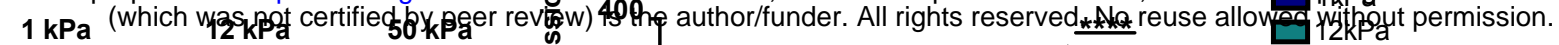

CB839: $=+-=+-\quad+=$

BPTES :

Glu-Tubulin $=-\infty$

Hsp 90 - - - - - -

Tubulin $-\ldots-\square$

Hsp 90

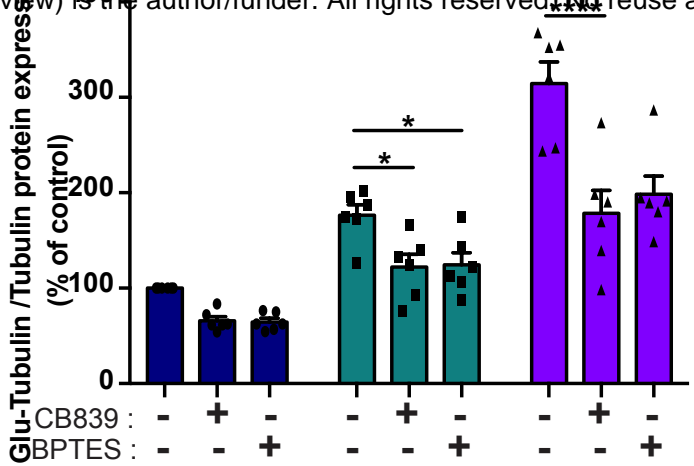

$\square 50 \mathrm{kPa}$

b

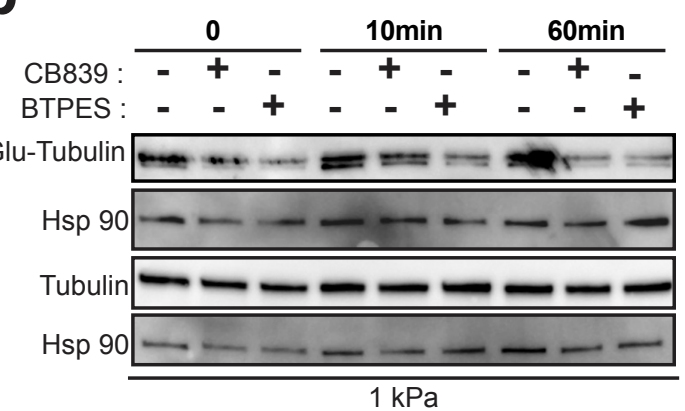

d
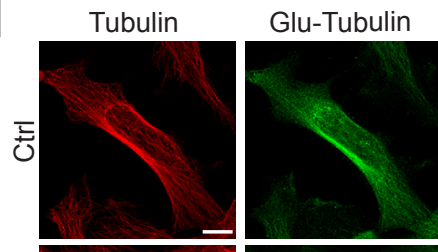

MERGE

ᄋ్
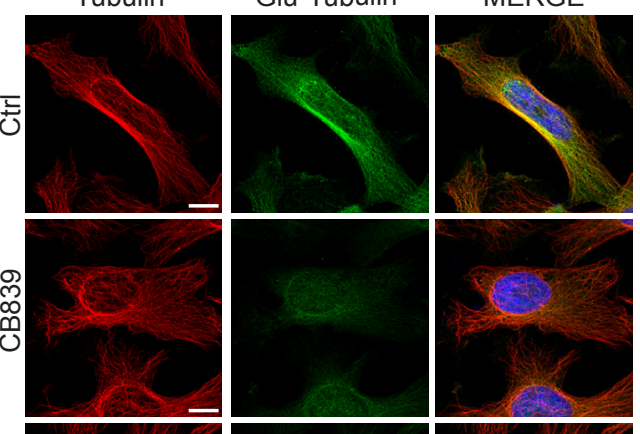

虫

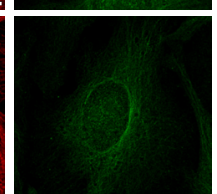

辛

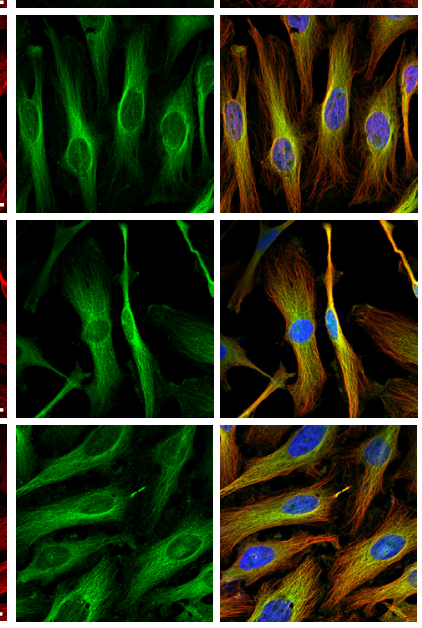

$50 \mathrm{kPa}$
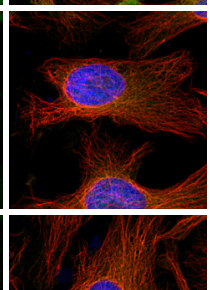

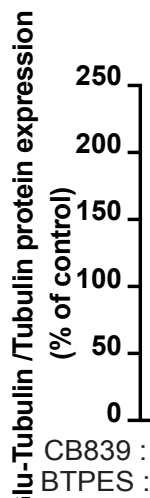
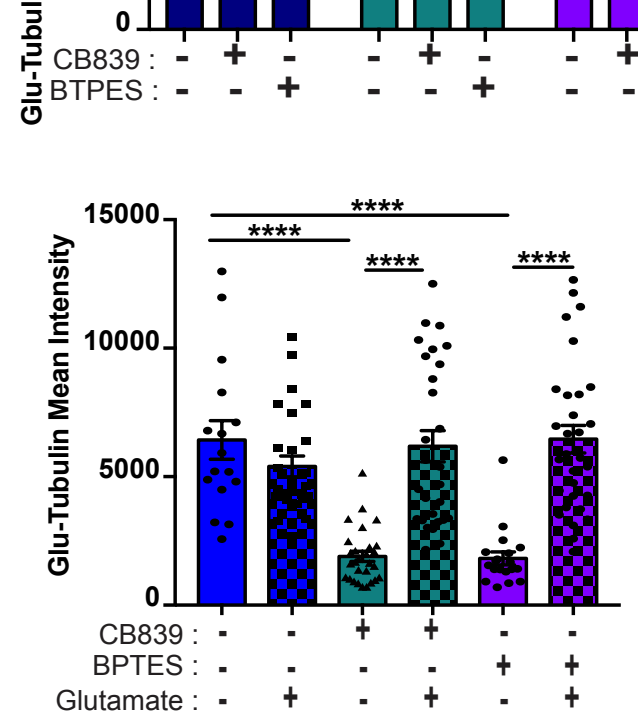

e
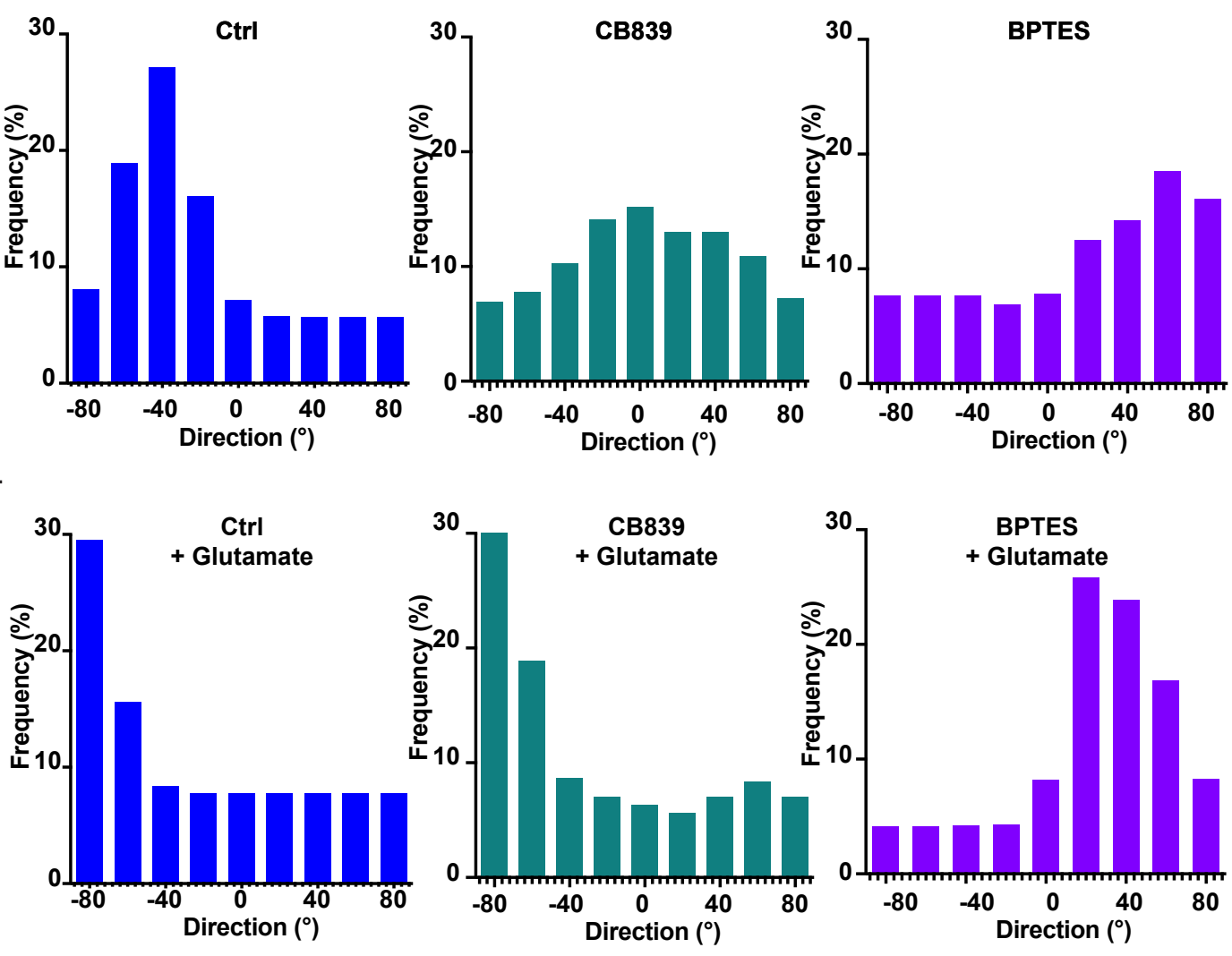

BPTES

+ Glutamate

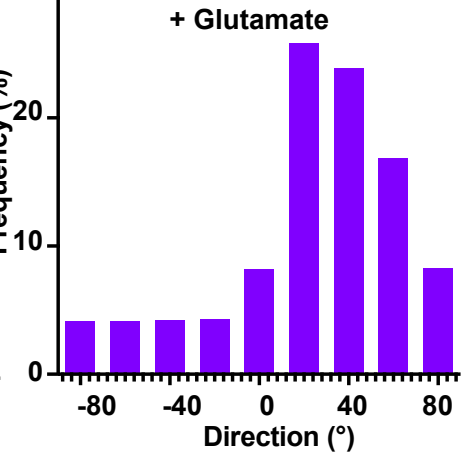

Extended Figure 4 

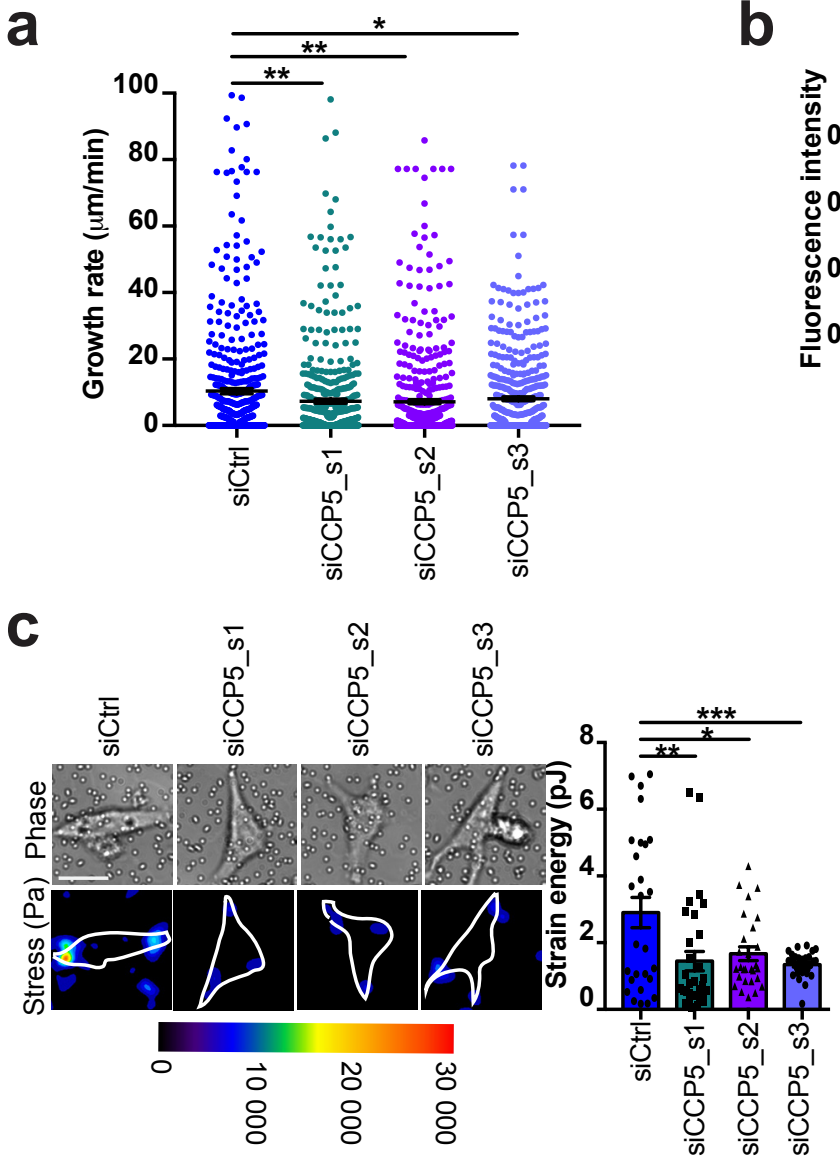

e
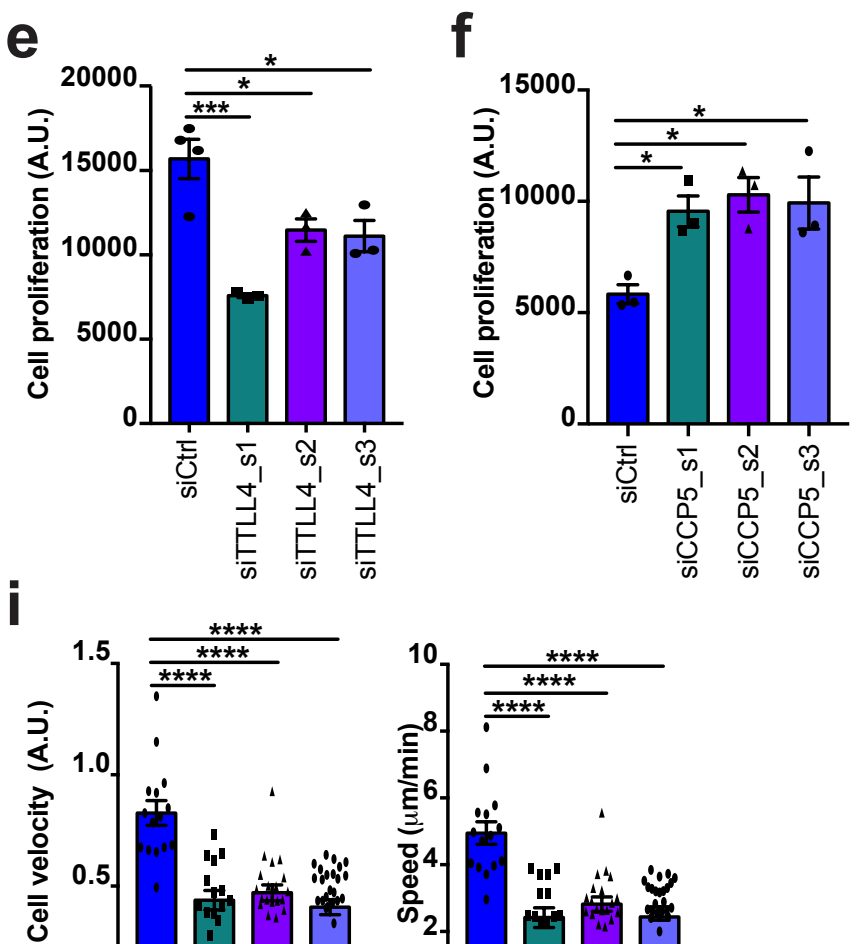

$=$
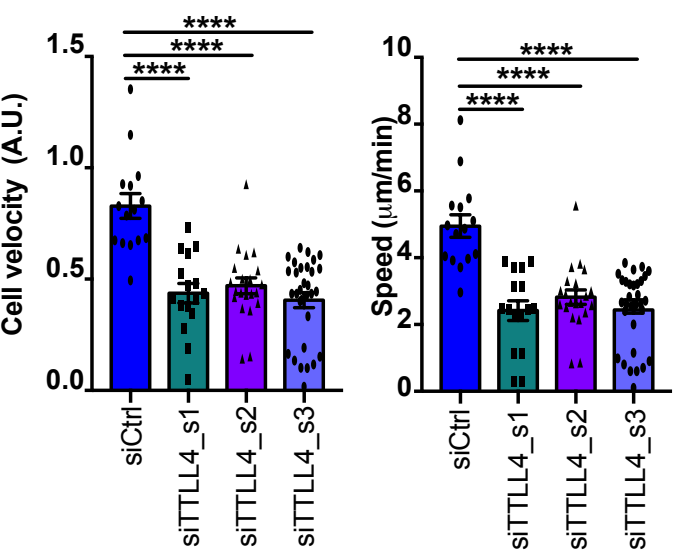
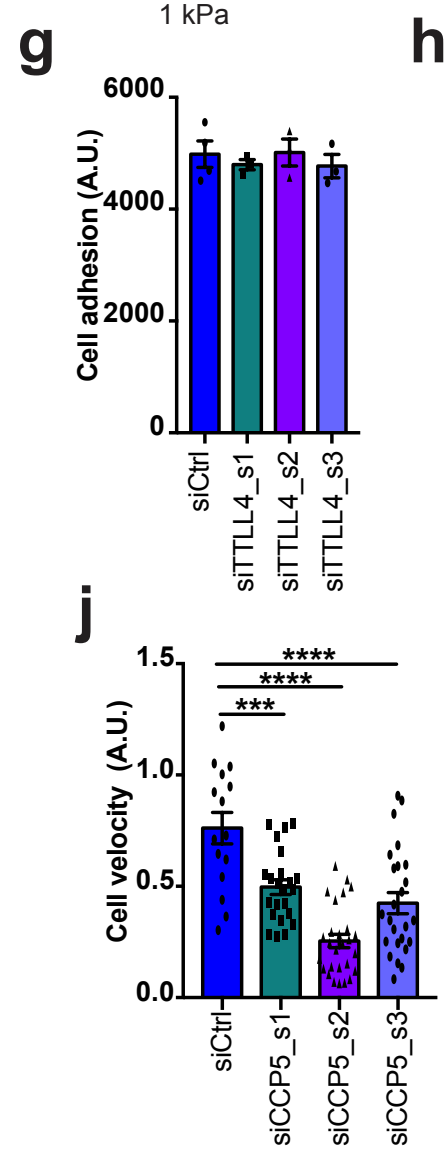
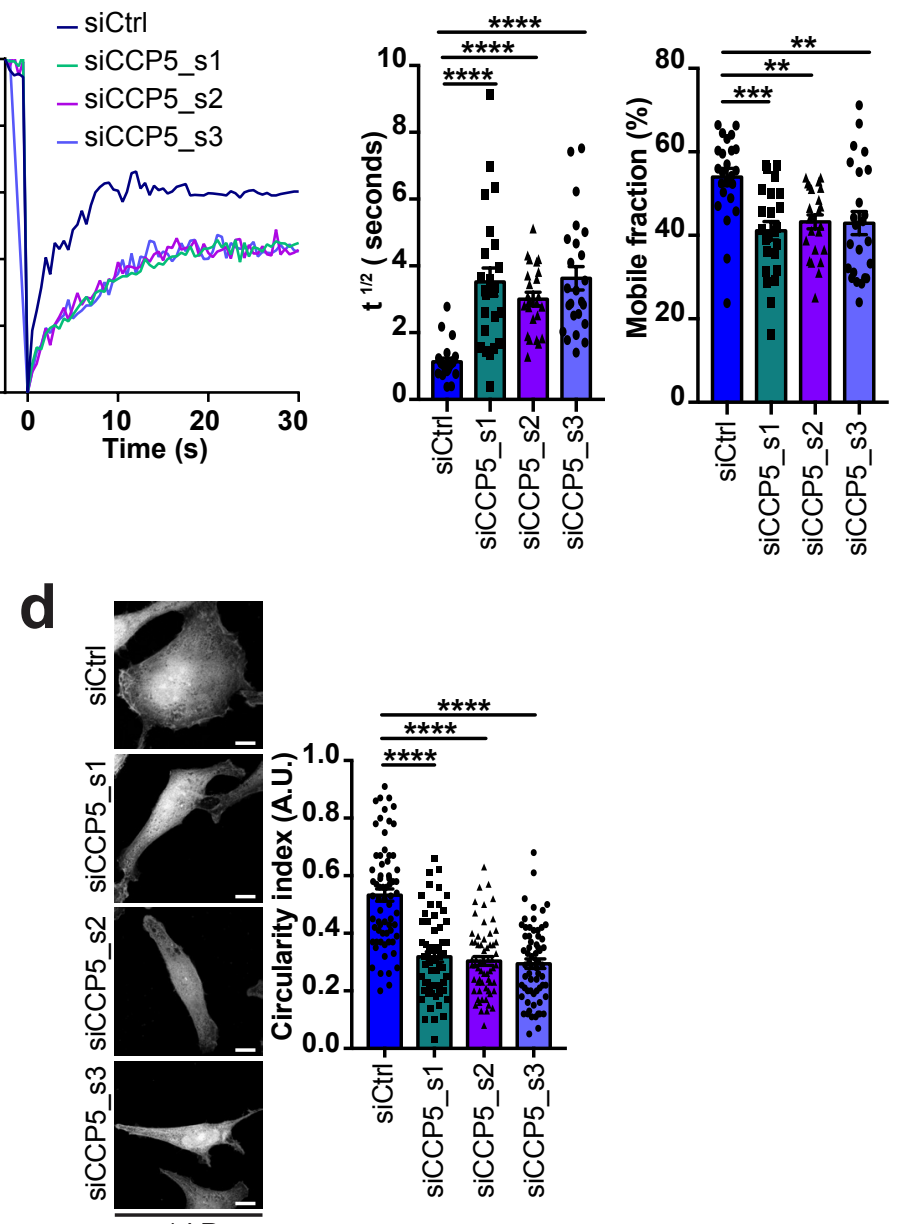

h
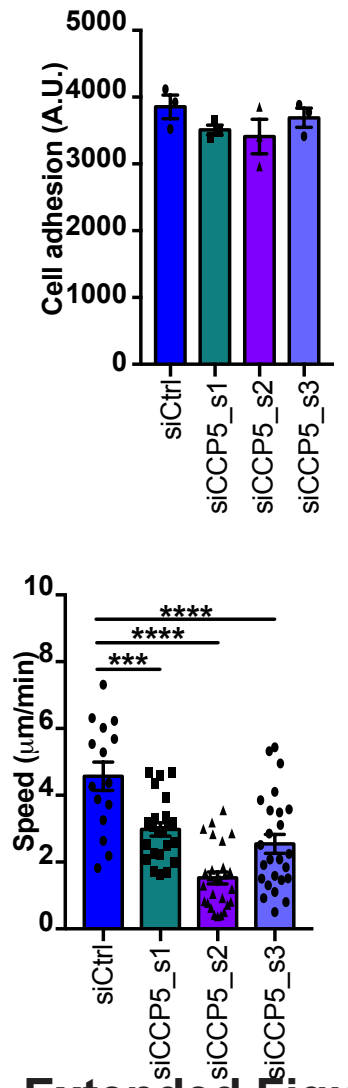

Extended Figure 6 


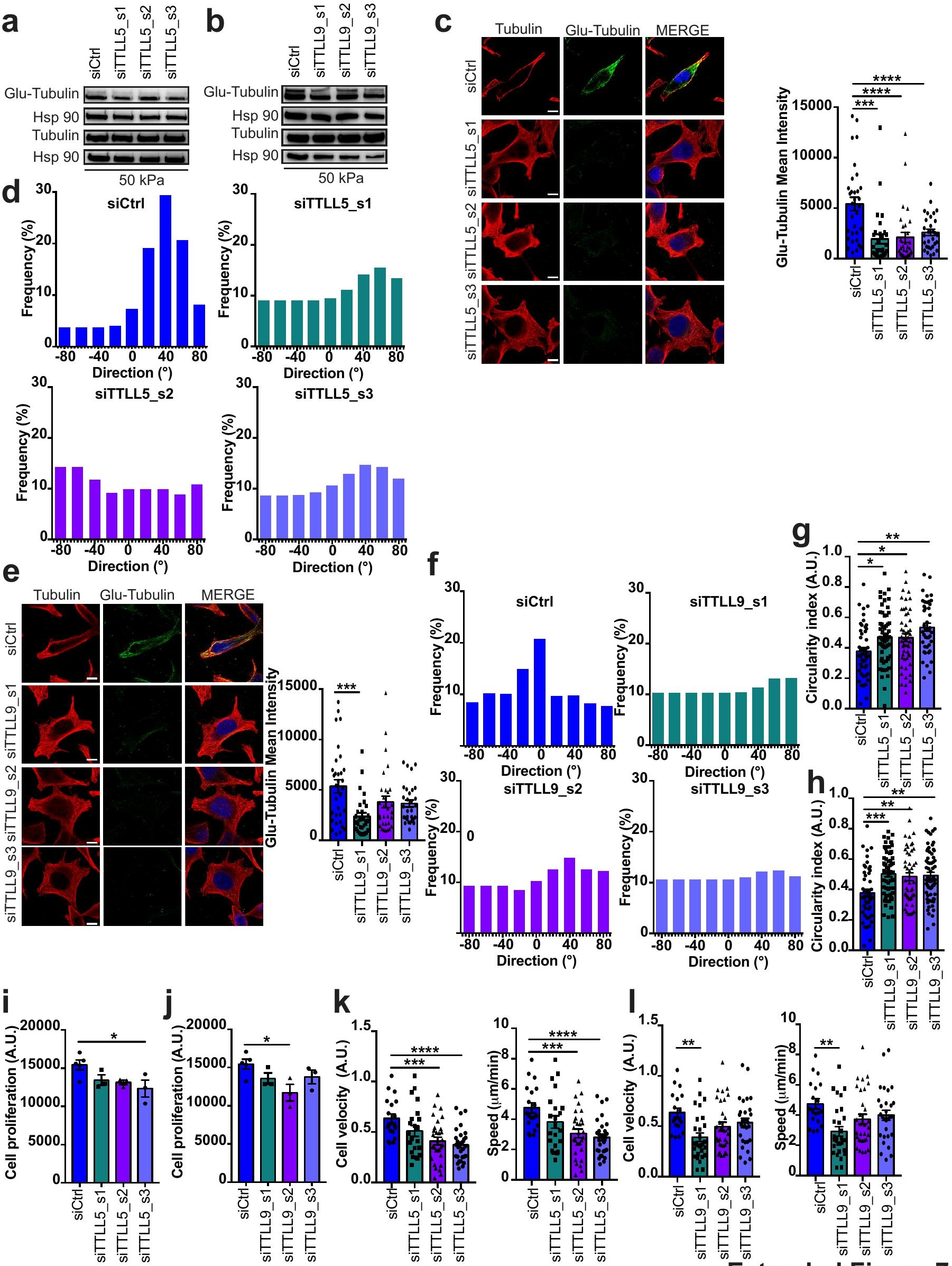

$\begin{array}{lll}a & & 5\end{array}$

\section{Tubulin \\ $50 \mathrm{kPa}$}

\section{f}

9

Extended Figure 7 
$\mathbf{a}$

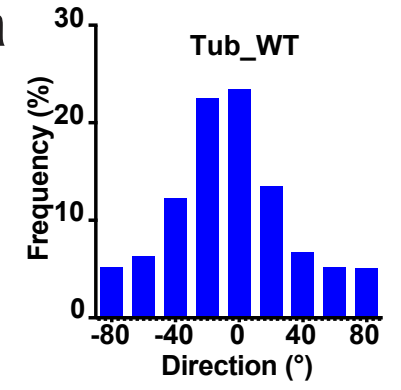

b
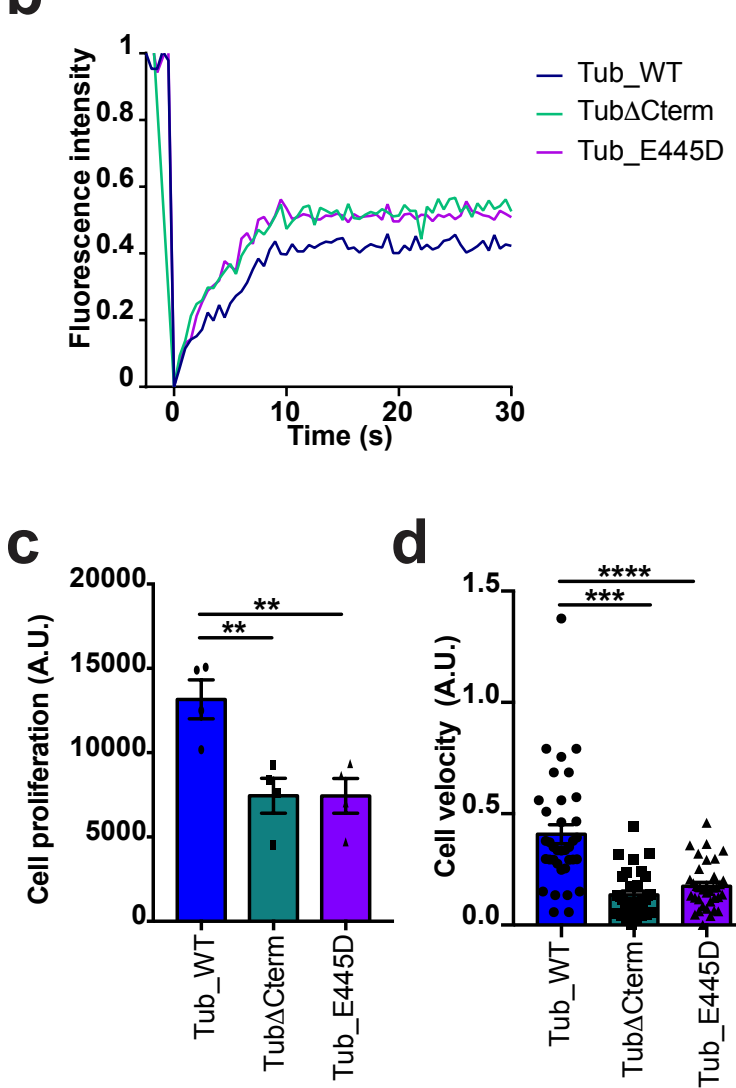
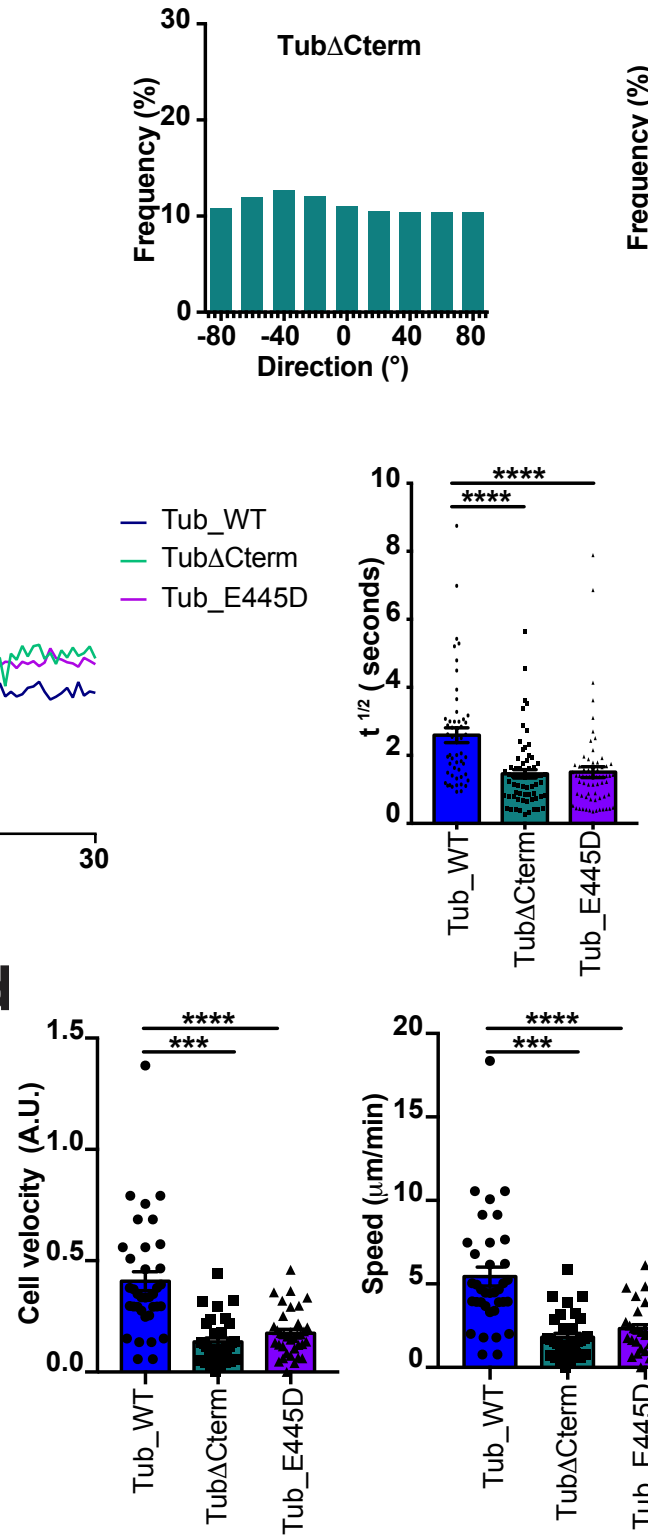
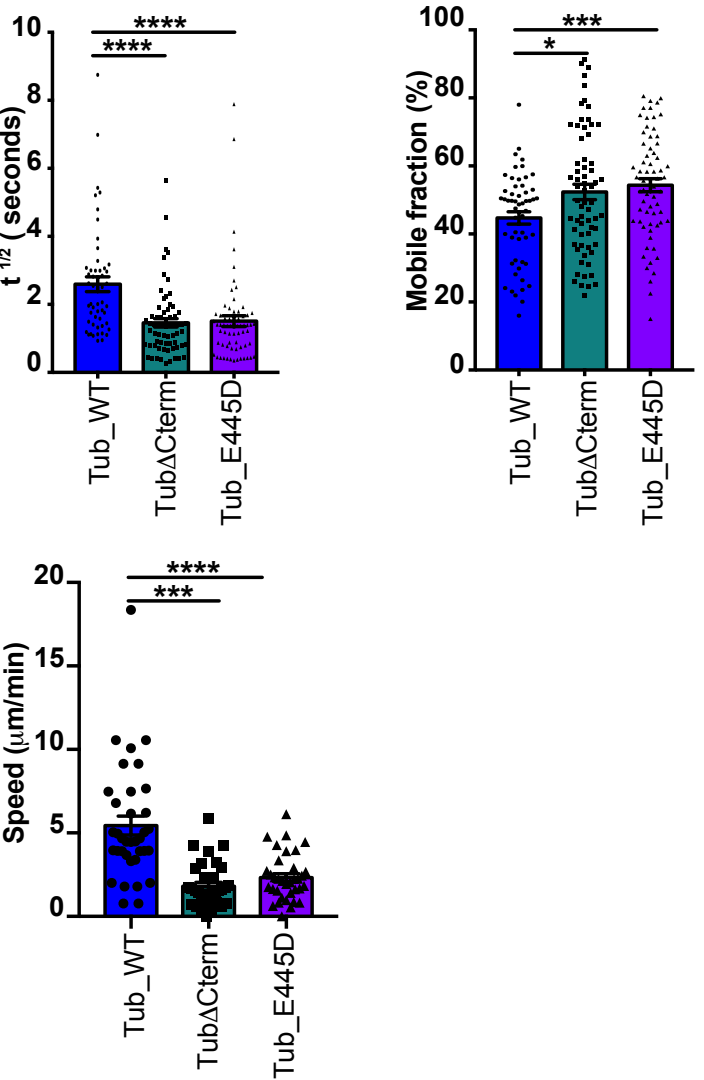